\title{
Host interleukin 6 production regulates inflammation but not tryptophan metabolism in the brain during murine GVHD
}

\author{
Ludovic Belle, ${ }^{1}$ Vivian Zhou, ${ }^{1}$ Kara L. Stuhr, ${ }^{2}$ Margaret Beatka, ${ }^{2}$ Emily M. Siebers, ${ }^{2}$ \\ Jennifer M. Knight, ${ }^{3}$ Michael W. Lawlor, ${ }^{4}$ Casey Weaver, ${ }^{5}$ Misato Hashizume, ${ }^{6}$ Cecilia J. Hillard, ${ }^{2}$ \\ and William R. Drobyski' \\ Department of Medicine, ${ }^{2}$ Department of Pharmacology and Toxicology, ${ }^{3}$ Department of Psychiatry, and ${ }^{4}$ Department of \\ Pathology and Laboratory Medicine, Medical College of Wisconsin, Milwaukee, Wisconsin, USA. ${ }^{5}$ University of Alabama \\ Birmingham, Birmingham, Alabama, USA. ${ }^{6}$ Chugai Pharmaceuticals Co., LTD., Shizuoka, Japan.
}

Graft-versus-host disease (CVHD) induces pathological damage in peripheral target organs leading to well-characterized, organ-specific clinical manifestations. Patients with GVHD, however, can also have behavioral alterations that affect overall cognitive function, but the extent to which CVHD alters inflammatory and biochemical pathways in the brain remain poorly understood. In the current study, we employed complementary murine GVHD models to demonstrate that alloreactive donor $T$ cells accumulate in the brain and affect a proinflammatory cytokine milieu that is associated with specific behavioral abnormalities. Host IL-6 was identified as a pivotal cytokine mediator, as was host indoleamine 2,3-dioxygenase (IDO-1), which was upregulated in CVHD in an IL-6-dependent manner in microglial cells and was accompanied by dysregulated tryptophan metabolism in the dorsal raphe nucleus and prefrontal cortex. Blockade of the IL-6 signaling pathway significantly reduced donor T cell accumulation, inflammatory cytokine gene expression, and host microglial cell expansion, but did not reverse GVHD-induced tryptophan metabolite dysregulation. Thus, these results indicate that inhibition of IL-6 signaling attenuates neuroinflammation, but does not reverse all of the metabolic abnormalities in the brain during CVHD, which may also have implications for the treatment of neurotoxicity occurring after other T cell-based immune therapies with IL-6-directed approaches.

Conflict of interest: The authors have declared that no conflict of interest exists.

Submitted: March 1, 2017

Accepted: June 6, 2017

Published: July 20, 2017

Reference information: JCI Insight. 2017;2(14):e93726. https://doi.org/10.1172/jici. insight.93726.

\section{Introduction}

Graft-versus-host disease (GVHD) is the primary complication associated with allogeneic hematopoietic stem cell transplantation (HSCT) and is the major cause of morbidity and mortality associated with this therapy (1-3). A prominent characteristic of GVHD is the presence of a proinflammatory milieu that is attributable to conditioning regimen-induced host tissue damage as well as secretion of inflammatory cytokines by alloactivated donor $\mathrm{T}$ cells and other effector cell populations $(4,5)$. These cytokines perpetuate GVHD through direct cytotoxic effects on host tissues (6-8), activation and/or priming of immune effector cells (9), and differentiation of proinflammatory $\mathrm{T}$ cell populations (i.e., $\mathrm{T}_{\mathrm{H}} 1$ and $\mathrm{T}_{\mathrm{H}} 17$ cells) from naive $\mathrm{T}$ cell precursors $(10,11)$. GVHD has been classified into 2 phases termed acute and chronic (1-3), which are distinguishable based on temporal characteristics as well as unique clinical and pathological manifestations. During the acute phase, GVHD generally targets a limited set of organs that includes the skin, liver, and gastrointestinal tract. Chronic GVHD, on the other hand, has more widespread organ involvement and clinical manifestations that are similar to those observed in autoimmune disorders

In addition to causing systemic tissue damage, GVHD has also been associated with significant impairments in overall quality of life $(12,13)$. Depression, anxiety, and mood alterations have been commonly reported in patients who develop this disease $(14,15)$. In fact, depression specifically has been shown to be a prognostic factor for worse overall survival in allogeneic HSCT recipients (16). 
Moreover, these behavioral abnormalities are often present in patients who have otherwise been cured of their disease. This problem is likely to grow with the advent of reduced intensity preparative regimens that are better tolerated and can be used in older patients, who are at increased risk for both brain dysfunction and GVHD (17). Traditional approaches for the treatment of these GVHD complications have involved antidepressant or anxiolytic agents that are used empirically and have not been validated in well-designed studies. Prior studies in animal models have demonstrated that alloreactive donor $\mathrm{T}$ cells are able to infiltrate the CNS and are associated with neuronal cell death $(18,19)$, suggesting that donor T cells can mediate pathological damage in the brain, similar to other GVHD target tissues. Furthermore, T cell-mediated inflammation has been correlated with behavioral abnormalities (18), similar to what has been reported in humans undergoing allogeneic HSCT $(20,21)$. However, mechanisms by which GVHD alters inflammatory and biochemical pathways in the brain and how these affect behavior remain poorly understood. Moreover, whether biological approaches to prevent systemic GVHD have similar efficacy within the CNS has not been critically examined. The goal of this study was to identify specific pathways by which GVHD induces inflammation and behavioral abnormalities in the brain, and determine whether inhibition of these pathways could attenuate the inflammatory milieu and restore behavioral function.

\section{Results}

GVHD induces a proinflammatory environment and effects behavioral alterations in the brain. To determine whether GVHD caused immunological alterations within the CNS, BALB/c mice were transplanted with MHCmismatched $\mathrm{B} 6$ bone marrow (BM) alone or together with adjunctive spleen cells to induce GVHD. We observed that GVHD animals had a significant increase in the total number of donor $\mathrm{CD} 4^{+}, \mathrm{CD}^{+}$, and $\alpha \beta^{+}$ $\mathrm{T}$ cells in the brain when compared with BM control mice 7 and 14 days after transplantation (Figure 1A). Notably, there were no NK or B cells detected in the brains of GVHD animals at these time points (data not shown). Infiltrating $\mathrm{CD} 4^{+}$and $\mathrm{CD} 8^{+} \mathrm{T}$ cells had an almost exclusively effector memory cell phenotype $\left(\mathrm{CD} 44^{+} \mathrm{CD} 62 \mathrm{~L}^{-}\right)$with few central memory $\left(\mathrm{CD} 44^{+} \mathrm{CD} 62 \mathrm{~L}^{+}\right)$and naive $\mathrm{T}$ cells $\left(\mathrm{CD} 44^{-} \mathrm{CD}^{-} \mathrm{L}^{+}\right)$present (Figure 1B). A similar increase in T cell numbers was observed when animals were assessed at 6 weeks, indicating persistence of donor T cells in the brain (Supplemental Figure 1, A and B; supplemental material available online with this article; https://doi.org/10.1172/jci.insight.93726DS1). Immunohistochemical analysis revealed increased $\mathrm{CD}^{+} \mathrm{T}$ cell infiltration in the brains of GVHD recipients when compared with BM control animals (Figure 1, C and D). Since T cell accumulation in GVHD target organs is typically associated with proinflammatory cytokine production, we conducted additional studies to determine if there was an inflammatory milieu in the brains of these animals. We observed that mRNA levels of IFN- $\gamma$, TNF- $\alpha$, and IL- 6 were all significantly increased in the brains of GVHD mice when compared with BM control animals (Figure 1E). To confirm that this was not a strain-dependent phenomenon, we repeated these experiments using a $\mathrm{B} 10 . \mathrm{BR} \rightarrow \mathrm{B} 6$ model and demonstrated that there was also increased accumulation of donor T cells (Supplemental Figure 2A), as well as augmented inflammatory cytokine production (Supplemental Figure 2B). To determine if CNS inflammation was associated with any behavioral abnormalities, behavior was assessed using the forced swim test (FST), an assay of behavioral coping in the face of an inescapable, aversive situation (22). Increased struggling is a dysfunctional response in this assay since it requires excessive amounts of energy to sustain. Using this endpoint, we observed that mice with GVHD exhibited significantly more struggling behavior compared with BM controls when examined 7 and 14 days after transplantation (Figure $1 \mathrm{~F}$ ). We also conducted the elevated plus maze (EPM) test, which provides animals with a choice between exploration of well-lit arms and remaining in a dark, enclosed space. Results of this study demonstrated that animals with GVHD had fewer entries and less time in the open arms, behaviors that are consistent with increased anxiety. However, this was observed only on day 14 and was less significant than results observed with the FST (Figure 1G). We therefore concluded that the EPM test was less sensitive to GVHD-induced behavioral changes, and therefore focused on the FST as a more robust behavioral readout for the remainder of our studies.

Tregs accumulate in the brain during GVHD but do not mitigate inflammation after adoptive transfer. Tregs have been shown to play an important role in modulating the severity of GVHD in peripheral target tissues (1-3); however, the role of Tregs in regulating inflammation within the CNS has not been examined. We observed that animals transplanted with BM alone had small percentages of $\mathrm{CD} 4^{+}$and $\mathrm{CD} 8^{+}$Tregs in the brain, but the absolute number of these cells was negligible due to the lack of lymphocyte accumulation in the CNS 

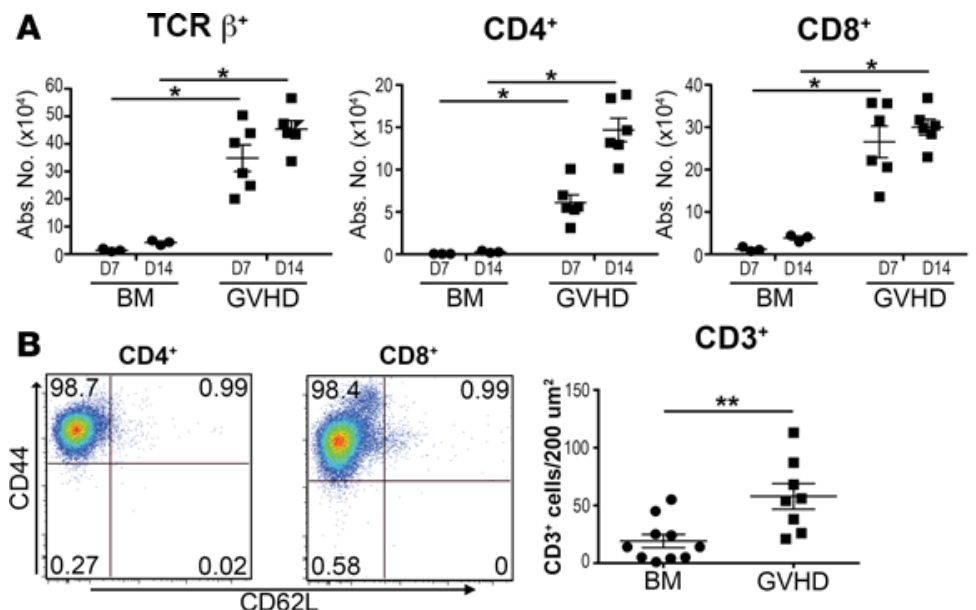

C

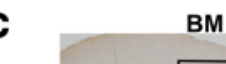

BM

$40 x$
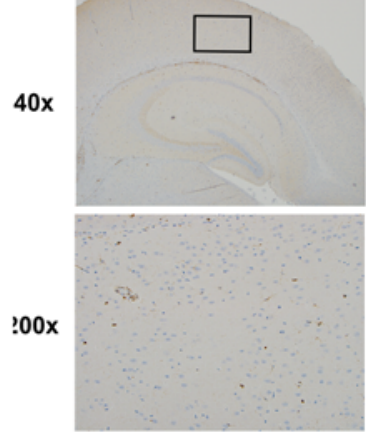

E
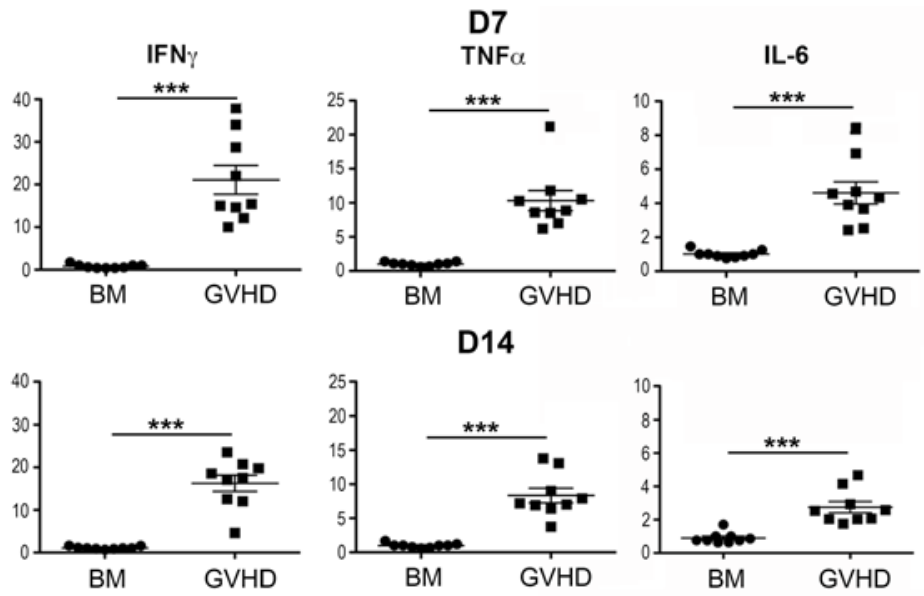

$\mathbf{F}$
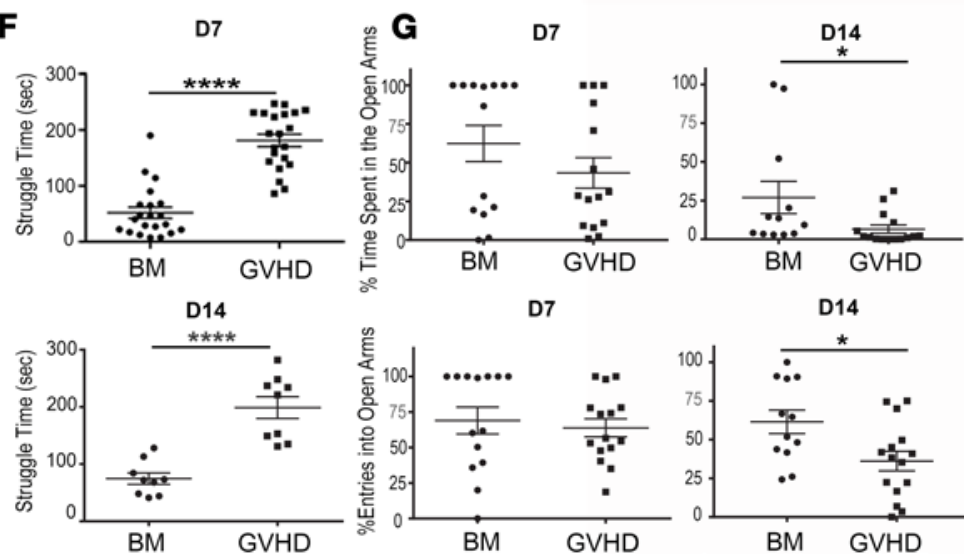

Figure 1. GVHD induces inflammation and behavioral alterations in the brain. (A) Lethally irradiated (900 cGy) BALB/c recipients were transplanted with $B 6$ bone marrow $(B M)$ alone $\left(5 \times 10^{6}\right.$ to $\left.10 \times 10^{6}\right)(\bullet, n=4)$ or B6 BM and B6 spleen cells (adjusted to yield an $\alpha \beta$ T cell dose of $0.6 \times 10^{6}$ cells) ( $\mathbf{\square}, n=$ 6). The absolute number of donor-derived TCR $\beta^{+}, \mathrm{CD} 4^{+}$, and CD8 ${ }^{+} T$ cells in the brain 7 and 14 days after transplantation is depicted. (B) Representative dot plots depicting CD44 and CD62L expression on $\mathrm{CD}^{+}$and $\mathrm{CD} 8^{+} \mathrm{T}$ cells from graft-versushost disease (CVHD) mice. (C) Total number of $\mathrm{CD}^{+} \mathrm{T}$ cells per 200-micron field in the brains of BALB/c mice reconstituted with $\mathrm{B} 6 \mathrm{BM}$ alone $(\bullet, n=10)$ or together with $\mathrm{B} 6$ spleen cells (GVHD) ( $\mathbf{\square}, n=8)$. (D) Representative section of the hippocampus from BM control and GVHD mice immunohistochemically stained for CD3. Original magnifications are $\times 40$ and $\times 200$, as shown. (E) IFN- $\gamma$, TNF- $\alpha$, and IL- 6 mRNA expression in the brains of BALB/c mice transplanted with B6 BM alone $(\bullet, n=$ 9) or B6 BM and B6 spleen cells ( $\mathbf{\square}, n=9$ ) 7 and 14 days after transplantation. (F) Time spent struggling (in seconds) of BALB/c mice transplanted with B6 BM alone $(\bullet, n=9-21)$ or B6 BM and spleen cells ( $\mathbf{\square}, n=9-21) 7$ and 14 days after transplantation. Results are from 2-4 experiments in all panels. (C) Percentage entries and time spent in open arms of elevated plus maze test in BALB/C mice transplanted with B6 BM alone $(\bullet, n=9-21)$ or B6 BM and spleen cells ( $\bullet, n=9-21) 7$ and 14 days after transplantation. Statistically significant differences were calculated using the 2 -tailed Mann-Whitney $U$ test and the 2-way ANOVA followed by Student's $t$ test. ${ }^{*} P<0.05$, ${ }^{* *} P$ $<0.01,{ }^{* * *} P<0.001,{ }^{* * *} P<0.0001$.

(Figure 2A). In contrast, while the frequency of $\mathrm{CD}^{+}$ Tregs was lower in GVHD brains, the number of these cells was significantly higher due to an overall increased number of donor-derived $\mathrm{CD}^{+}{ }^{+} \mathrm{T}$ cells in this tissue site. Similarly, the absolute number of $\mathrm{CD}^{+}$Tregs, which are all essentially induced Tregs (iTregs), was also augmented in animals with GVHD. Since the majority of CD4+ Tregs transferred in the BM graft are natural Tregs (nTregs), we examined whether $\mathrm{CD}^{+}$iTregs could also accumulate in the brain during GVHD. Mice that were reconstituted with B6 Rag-1 BM plus CD4 ${ }^{+}$and $\mathrm{CD}^{+}{ }^{+}$Foxp3 $3^{\text {EGFP- }} \mathrm{T}$ cells had a significant increase in both iTreg populations when compared with BM control mice (Figure $2 \mathrm{~B}$ ), indicating that conventional $\mathrm{CD}^{+}$and $\mathrm{CD}^{+} \mathrm{T}$ cells could express Foxp3 and traffic to the brain under inflammatory conditions. Since IL-10 is one of the mechanistic pathways by which Tregs mitigate GVHD (23), we examined IL-10 production within the CNS. We observed that IL-10 mRNA levels were significantly increased in the brains of GVHD animals relative to BM controls (Figure 2C). To identify the IL-10-producing $\mathrm{T}$ cell populations we employed an IL-10 reporter mouse (10BiT.Foxp3 ${ }^{\text {EGFP }}$ ) to delineate specific $\mathrm{CD}^{+}$and $\mathrm{CD} 8^{+} \mathrm{T}$ cell subpopulations. These studies revealed that there was a substantial percentage of both conventional $\mathrm{CD}^{+}$and $\mathrm{CD} 8^{+} \mathrm{T}$ cells that secreted IL-10, which resulted in an increase in the absolute number of these cells (Figure 2D). Furthermore, the absolute number of $\mathrm{CD}^{+}$and $\mathrm{CD}^{+}{ }^{+}$Foxp $^{+} \mathrm{T}$ cells that produced IL-10 was also augmented relative to control 
A

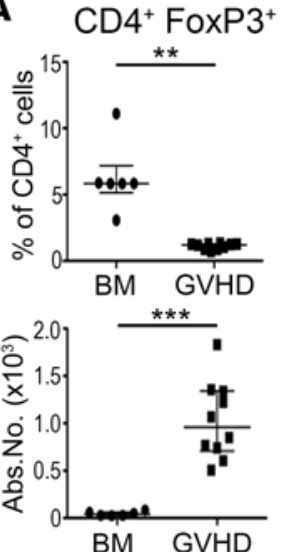

$\mathrm{CD}^{+} \mathrm{FoxP}^{+}$
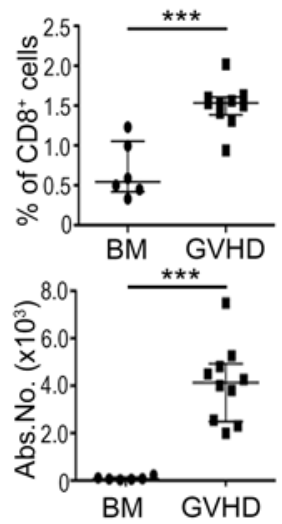

D
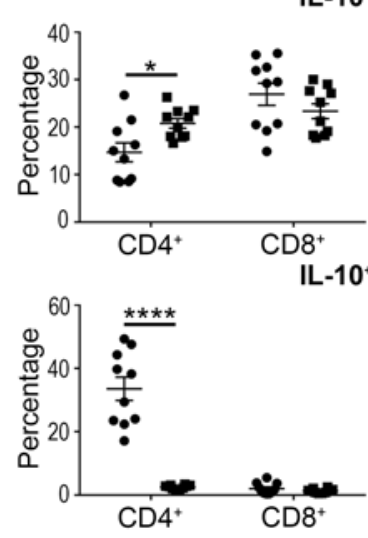

$\mathbf{F}$

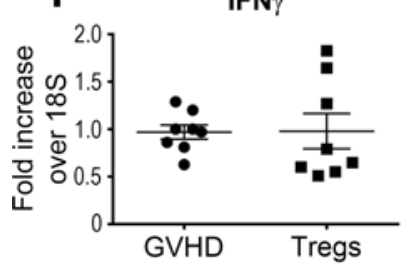

G Fox $3^{+}$in Thy $1.2^{+}$gate

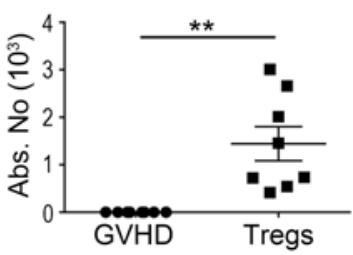

IL-10+ Tregs

IL-10+ $\mathrm{T}$ conv
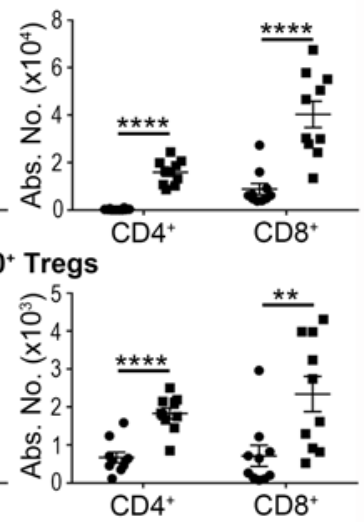

IL-6
B
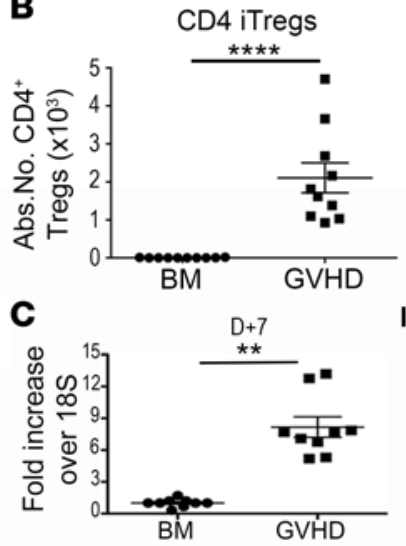

E

Thy $1.1^{+}$TCR $\beta^{+}$

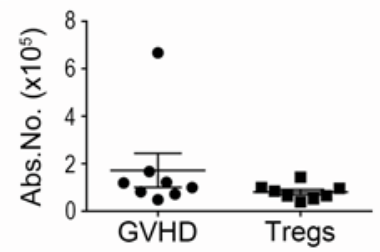

Thy $1.1^{+}$CD8 ${ }^{+}$

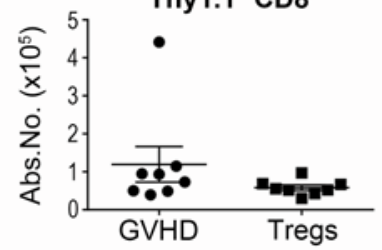

TNF $\alpha$

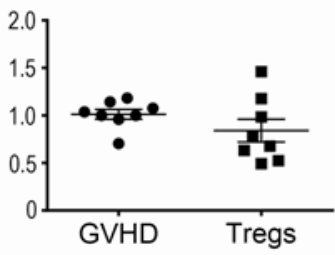

FoxP3 ${ }^{+}$in Thy $1.2^{+}$gate
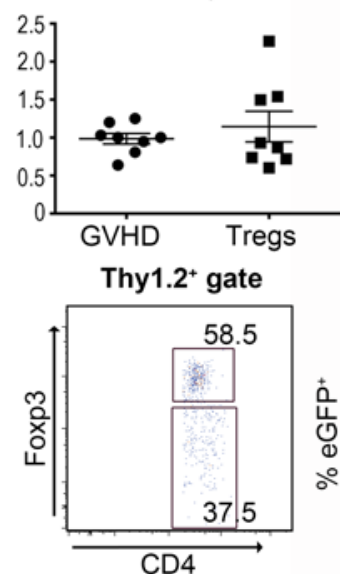

Thy $1.2^{+}$gate

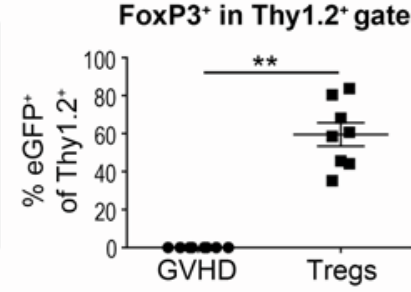

Figure 2. Treg cell accumulation in the brain during graft-versus-host disease (GVHD). (A) Irradiated BALB/c recipients were transplanted with B6 Foxp3 $3^{\text {ECFP }}$ bone marrow (BM) alone $(\bullet, n=6)$ or together with B6 Foxp $3^{\text {ECFP }}$ spleen cells (adjusted to yield an $\alpha \beta$ T cell dose of $0.6 \times 10^{6}$ cells) $(\mathbf{n}, n=10)$. The percentage and absolute number of $\mathrm{CD} 4^{+}$or $\mathrm{CD} 8^{+} \mathrm{Foxp}^{+} \mathrm{T}$ cells in the brain 14 days after transplantation is shown. (B) BALB/c mice were transplanted with B6 Rag-1 BM alone $\left(5 \times 10^{6}\right)$ or together with sorted $\mathrm{CD} 4^{+}\left(0.5 \times 10^{6}\right)$ and $\mathrm{CD}^{+}\left(0.3 \times 10^{6}\right)$ Foxp $^{\text {ECFP- }}$ T cells. The absolute number of CD4 ${ }^{+}$or $C D 8^{+}$Foxp $3^{+}$ T cells in the brain is shown on day 14. iTregs, induced Tregs. (C) IL-10 mRNA expression in the brains of animals transplanted with B6 BM alone $(\bullet, n=9)$ or B6 BM and B6 spleen cells ( $(\mathbf{n}, n=9) 7$ and 14 days after transplantation. (D) BALB/c animals transplanted with BM alone $(\bullet, n=10)$ or together with spleen cells from 10BiT.Foxp $3^{\text {ECFP }}$ reporter mice $(\mathbf{a}, n=10)$. The frequency and absolute number of conventional (conv) and regulatory CD4 ${ }^{+}$and CD8 $8^{+} T$ cells expressing IL-10 are depicted. (E) Irradiated BALB/c mice transplanted with B6.PL BM and spleen cells $\left(0.6 \times 10^{6} \alpha \beta^{+}\right.$T cells) (GVHD) along with $0.6 \times 10^{6}$

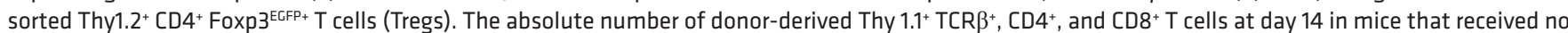
Tregs $(\bullet, n=8)$ or Tregs $(\mathbf{\square}, n=8)$ is shown. (F) IFN- $\gamma$, IL-6, and TNF- $\alpha$ mRNA expression in the brains of GVHD control animals $(\bullet, n=8)$ or mice that also received adoptively transferred Tregs $(\mathbf{m}, n=8)$. (G) The absolute number of Thy1.2 $2^{+}$Tregs in the brain of BALB/c mice transplanted with B6 BM and spleen cells $(\bullet, n=6)$ or B6 BM and spleen cell plus sorted CD4+ Foxp3 $3^{\mathrm{ECFP}+}$ Tregs $(\boldsymbol{\square}, n=8)$. Representative dot plot and scatterplot of the percentage of Thy1.2 $2^{+}$ Tregs that retained expression of Foxp3 in mice that received sorted Tregs. Results are from 2 experiments in all panels. Statistically significant differences were calculated using the 2-tailed Mann-Whitney $U$ test. ${ }^{*} P<0.05$, ${ }^{* *} P<0.01,{ }^{* *} P<0.001,{ }^{* * *} P<0.0001$. 
A

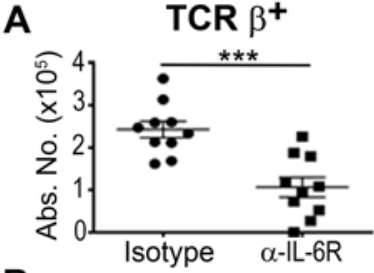

B

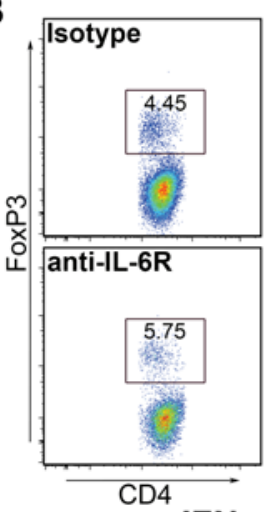

C

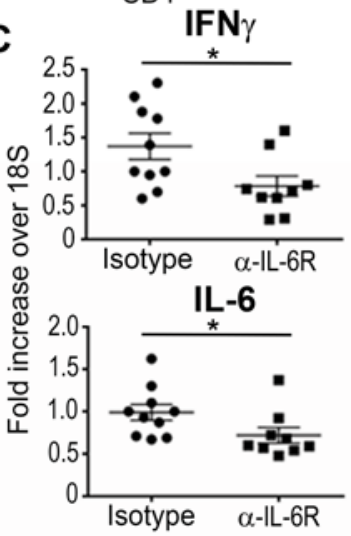

CD4 ${ }^{+}$

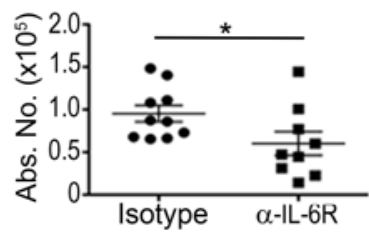

$\mathrm{CD}^{+}{ }^{+}$oxp $3^{+}$
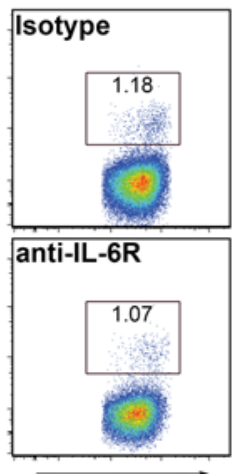

CD8
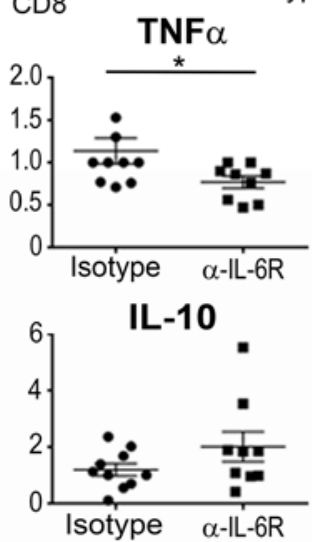

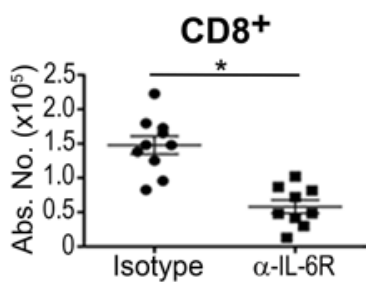

$\mathrm{CD}^{+} \mathrm{FoxP}^{+}$
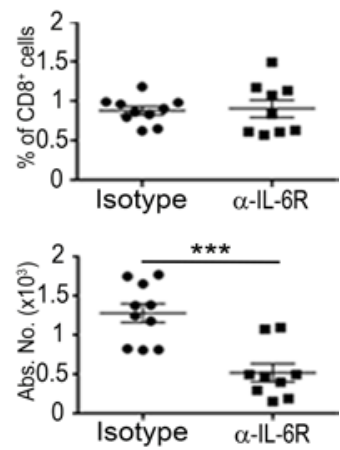

D。

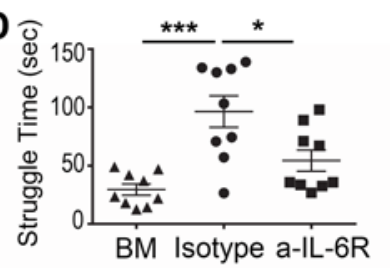

Figure 3. Blockade of IL-6 signaling reduces inflammation in the brain during graft-versus-host disease. (A) Lethally irradiated $B A L B / c$ recipients were transplanted with $\mathrm{B} 6$ bone marrow (BM) and B6 spleen cells (adjusted to yield an $\alpha \beta$ T cell dose of $0.6 \times 10^{6}$ cells) and then treated with either an isotype control $(\bullet$, $n=10$ ) or an anti-IL-6 receptor ( $\alpha$-IL-6R) antibody ( $\mathbf{\square}, n=9)$ on days 0 and 7 . The absolute number of donor-derived TCR $\beta^{+}$, $\mathrm{CD}^{+}$, and $\mathrm{CD} 8^{+} \mathrm{T}$ cells in the brain 14 days after transplantation is depicted. (B) $\mathrm{BALB} / \mathrm{c}$ mice were transplanted with BM and spleen cells from Foxp $3^{\mathrm{ECFP}}$ animals, and then treated with an isotype control $(\bullet, n=10)$ or anti-IL-6R antibody $(\mathbf{\bullet}, n=9)$. Representative dot plots along with the frequency and absolute number of $\mathrm{CD} 4^{+}$ and $\mathrm{CD}^{+}{ }^{+} \mathrm{Foxp}^{+} \mathrm{T}$ cells are shown. (C) IFN- $\gamma$, TNF- $\alpha$, IL- 6 , and IL-10 mRNA expression in the brain of BALB/c recipient mice treated with either an isotype control $(\bullet$, $n=10)$ or anti-IL-6R antibody $(\mathbf{\square}, n=9)$ as in panel B. (D) Time spent struggling in a forced swim test (in seconds) of BALB/c recipients transplanted with $\mathrm{B} 6 \mathrm{BM}$ alone $(\boldsymbol{\Delta}, n=9)$ or together with spleen cells and then treated with an isotype $(\bullet, n=9)$ or anti-IL-6R antibody ( $(\mathbf{\square}, n=9) 14$ days after transplantation. Results are from 2-3 experiments in all panels. Statistically significant differences were calculated using the 2-tailed Mann-Whitney $U$ test and the 2-way ANOVA followed by Student's $t$ test. ${ }^{*} P<0.05,{ }^{* *} P<0.001$.

animals, but was 10 -fold less than the number of conventional $\mathrm{T}$ cells that were IL-10+ $0^{+}$. We then conducted studies to determine whether the adoptive transfer of Tregs could mitigate inflammation within the CNS in a comparable fashion to what has been observed in the periphery (23). We observed that animals reconstituted with Tregs at the time of transplantation had no difference in the absolute number of donor-derived Thy $1.1^{+}$ $\mathrm{T}$ cells (Figure 2E), nor was there any reduction in the gene expression of proinflammatory cytokines (Figure $2 \mathrm{~F}$ ). This was not due to an inability of adoptively transferred Tregs to traffic into the brain, as Thy $1.2^{+}$ Tregs were detectable; however, approximately $40 \%$ had lost expression of Foxp3 when examined 2 weeks after transplantation (Figure 2G). Collectively, these data indicated that Tregs were capable of infiltrating the brain and producing IL-10, but did not effectively mitigate inflammatory changes even after adoptive transfer due, in part, to instability of Foxp3 expression.

Antibody blockade of IL-6 signaling attenuates inflammation in the brain during GVHD. IL-6 has been shown to be associated with dysfunction of mood and cognition in animal models $(24,25)$ and IL-6 receptors (IL6Rs) are expressed on microglia and astrocytes within the brain (26-28). Moreover, IL-6 production within the brain appears to contribute to the expression of other inflammatory cytokines such as TNF- $\alpha$ and IL-1 $\beta$ (29), suggesting that IL-6 promotes an inflammatory environment within the CNS. Given that anti-IL-6R antibody treatment suppresses peripheral inflammation, we examined whether this treatment would also alter the GVHD-induced inflammatory milieu within the brain. Recipient animals treated with an anti-IL$6 \mathrm{R}$ antibody had a significant reduction in the absolute number of donor-derived $\mathrm{CD} 4^{+}, \mathrm{CD} 8^{+}$, and $\alpha \beta^{+} \mathrm{T}$ cells in the brains when compared with isotype antibody-treated mice (Figure 3A). No difference, however, was observed in the percentage or absolute number of $\mathrm{CD} 4^{+}$Tregs, and there was actually a corresponding decrease in total $\mathrm{CD} 8^{+}$Treg numbers in animals that were administered anti-IL-6R antibody (Figure 3B). mRNA levels of IFN- $\gamma$, TNF- $\alpha$, and IL-6, but not IL-10, were also significantly decreased in anti-IL-6R anti- 

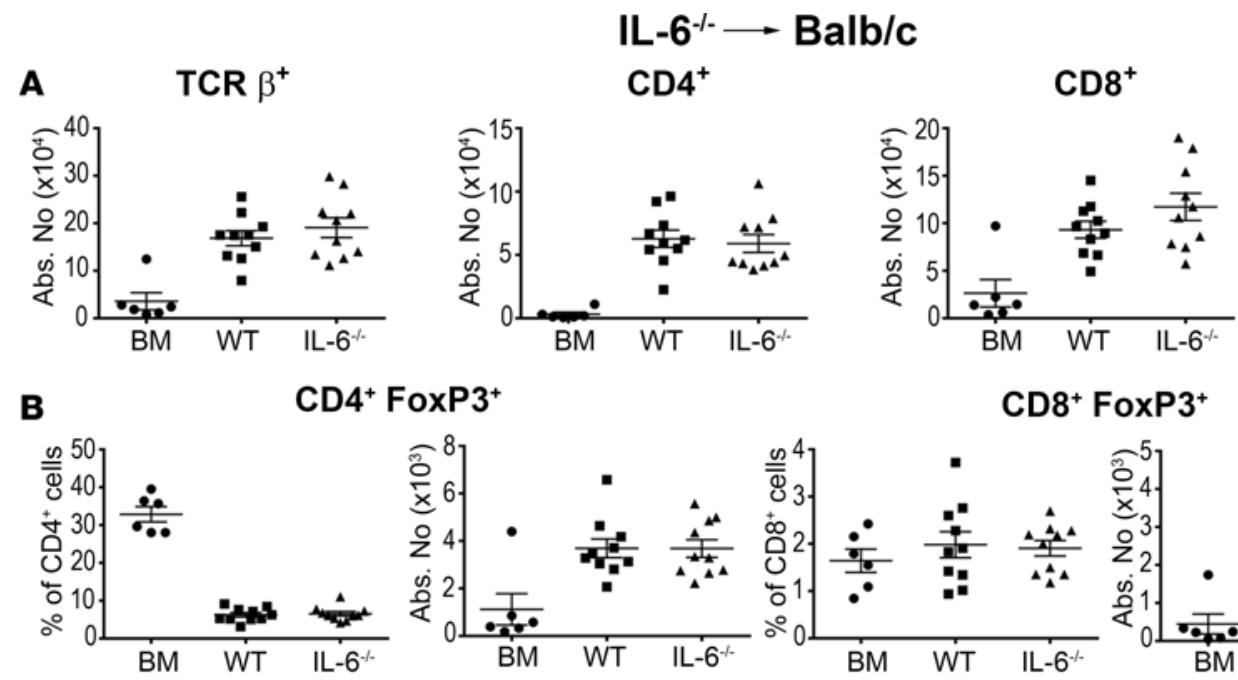

$\mathrm{CD}^{+}$FoxP3 $^{+}$
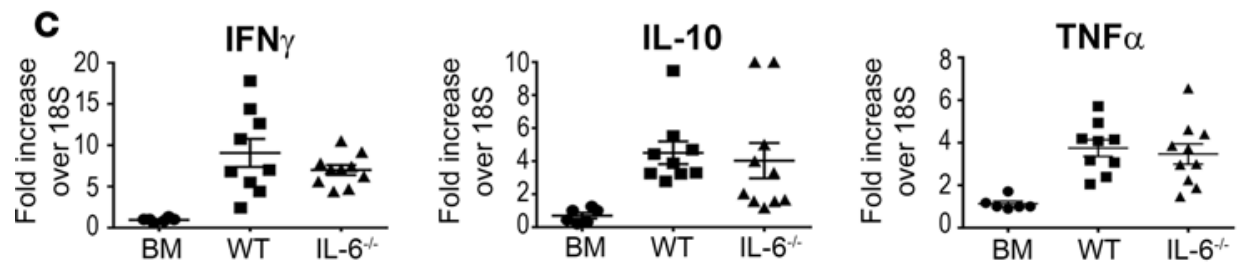

Figure 4. Donor IL-6 production is not required for neuroinflammation during graft-versus-host disease. (A) BALB/c mice were transplanted with B6

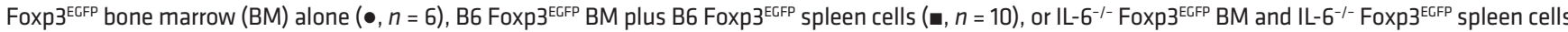
$(\boldsymbol{\Lambda}, n=10)$. The absolute number of donor-derived TCR $\beta^{+}, \mathrm{CD} 4^{+}$, and $\mathrm{CD} 8^{+}$T cells in the brain 14 days after transplantation is depicted. (B) BALB/C mice were transplanted with B6 BM alone $(\bullet, n=6)$, BM and spleen cells from Foxp3 $3^{\text {ECFP }}$ mice $(\boldsymbol{\bullet}, n=9)$, or B6 BM and spleen cells from IL-6 $6^{-1-}$ Foxp $3^{\text {ECFP }}$ animals $(\boldsymbol{\Delta}, n=$ 9-10). The frequency and absolute number of $C D 4^{+}$and $C D 8^{+}$Foxp3 $^{+}$T cells is shown. (C) IFN- $\gamma$, IL-10, and TNF- $\alpha$ mRNA expression in the brains of BALB/C mice transplanted with B6 BM alone $(\bullet, n=6)$, B6 Foxp3 ${ }^{\mathrm{ECFP}}$ BM and spleen cells $(\mathbf{\square}, n=9)$, or IL-6 ${ }^{-1-}$ Foxp3 ${ }^{\text {ECFP }}$ BM and spleen cells $(\boldsymbol{\Lambda}, n=9) 14$ days after transplantation. Statistically significant differences were calculated using the 2-tailed Mann-Whitney $U$ test and the 2-way ANOVA followed by Student's $t$ test.

body-treated animals (Figure 3C), indicating that blockade of peripheral IL-6 signaling preferentially targeted the effector, as opposed to the regulatory, arm of the immune system in the brain. To determine whether IL-6 inhibition had any functional consequences, we conducted the FST in these 2 cohorts and observed that anti-IL-6R antibody-treated mice engaged in significantly less struggling compared with isotype-treated controls (Figure 3D). Collectively, these studies indicated that blockade of peripheral IL-6 signaling reduced GVHD-associated inflammation in the brain and also normalized the behavioral responses in the FST.

Host IL-6 production is critical for inducing CNS inflammation during GVHD. Since IL-6 is produced by a wide variety of cells, including microglial and $\mathrm{T}$ cells, both donor and recipient cells have the potential to modulate GVHD severity. To further define the relevant contribution of host versus donor IL-6 production, we conducted experiments using IL- $6^{-1-}$ FoxP $3^{\mathrm{EGFP}}$ reporter mice to determine the relative effects of recipient and donor IL-6 production on conventional T cells and Tregs within the CNS. We observed that there was no difference in the absolute number of donor-derived conventional (Figure 4A) or regulatory (Figure 4B) $\mathrm{CD}^{+}$or $\mathrm{CD} 8^{+} \mathrm{T}$ cells in the brain of animals that were reconstituted with either wild-type or IL- $6^{-/} \mathrm{BM}$ grafts. Furthermore, there was no difference in inflammatory gene expression (Figure 4C), indicating that donor-derived IL-6 had no appreciable effect on neuroinflammation. Conversely, IL-6 ${ }^{-/-}$recipients reconstituted with MHC-incompatible BM grafts had a significant reduction in the accumulation of donor-derived conventional $\mathrm{T}$ cells in the brain compared with wild-type recipients (Figure 5A). Treg reconstitution was not altered except for an actual reduction in the absolute number of $\mathrm{CD}^{+}$Tregs in IL-6 $6^{-/-}$recipients (Figure 5B). Inflammatory gene expression was also reduced in these mice (Figure 5C), indicating that host IL-6 production promoted a proinflammatory milieu within the CNS during GVHD. FST results in the B10. $\mathrm{BR} \rightarrow \mathrm{B} 6$ model revealed that wild-type recipient mice had increased struggling compared with BM controls (Figure 5D); however, the behavioral change was not as large as it was in the B6 $\rightarrow \mathrm{BALB} / \mathrm{c}$ model (Figure $1 \mathrm{~F})$. Moreover, the absence of host IL-6 production had no salutary effect on this behavioral endpoint, contrary to what we observed with anti-IL-6R antibody blockade (Figure 3D). 

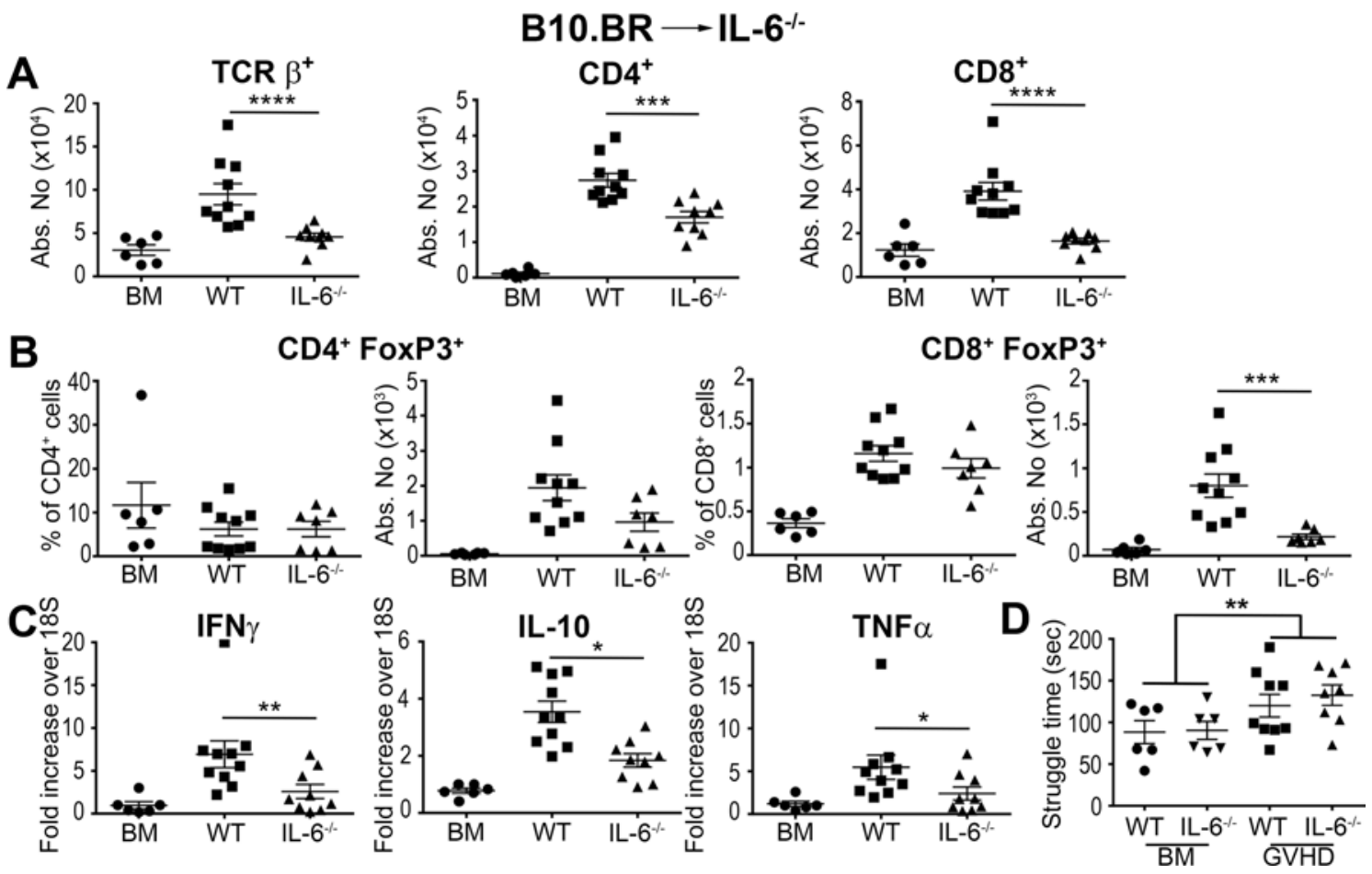

Figure 5. Host IL-6 production regulates inflammation in the brain during graft-versus-host disease (GVHD). (A-C) Lethally irradiated (1,100 cGy) B6 ( $\square, n$

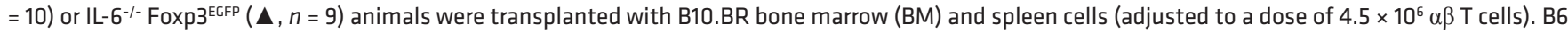
$(\bullet, n=6)$ mice reconstituted with B10.BR BM alone served as controls. (A) The absolute number of donor-derived TCR $\beta^{+}, \mathrm{CD} 4^{+}$, and CD8 ${ }^{+} \mathrm{T}$ cells in the brain 14 days after transplantation. (B) The frequency and absolute number of donor CD4+ and CD8 $8^{+}$Foxp3 $3^{+}$T cells. (C) IFN- $\gamma$, IL-10, and TNF- $\alpha$ mRNA expression in the brain. (D) Lethally irradiated $(1,100 \mathrm{cGy}) \mathrm{B} 6(\mathbf{\square}, n=9)$ or IL-6 ${ }^{-1-} \operatorname{Foxp}^{\mathrm{ECFP}}(\boldsymbol{\Delta}, n=8)$ animals were transplanted with B10.BR BM and spleen cells (adjusted to a dose of $4.5 \times 10^{6} \alpha \beta$ T cells). B6 $(\bullet, n=6)$ or IL- $6^{-/-} \operatorname{Foxp}^{\text {ECFP }}(\boldsymbol{\nabla}, n=6)$ mice reconstituted with BALB/c BM alone served as controls. Time spent struggling in a forced swim test is depicted. Results are from 2 experiments in all panels. Statistically significant differences were calculated using the 2-tailed Mann-Whitney $U$ test and the 2-way ANOVA followed by Student's $t$ test. ${ }^{*} P<0.05,{ }^{* *} P<0.01,{ }^{* * *} P<0.001,{ }^{* * * *} P<0.0001$.

Host indoleamine 2,3-dioxygenase regulates neuroinflammation during GVHD. We then examined the role of indoleamine 2,3-dioxygenase (IDO-1), since IL-6 has been shown to upregulate IDO-1 expression under inflammatory conditions in the brain $(30,31)$. Moreover, depletion of tryptophan has been observed in cancer patients treated with immunotherapy (i.e., IL-2 and IFN- $\alpha$ ) who develop depression (32). IDO-1 mRNA expression was significantly increased in the brains of mice with GVHD when compared with BM control animals at both 7 and 14 days after transplantation (Figure 6A). We observed that administration of the anti-IL-6R antibody resulted in a significant decrease in IDO-1 mRNA levels (Figure 6B), and that IDO-1 expression was lower in transplantation studies only when recipient (Figure 6C), but not donor (Figure 6D), animals were IL-6 deficient, indicating that host IL-6 regulated IDO-1 expression. Mice reconstituted with IDO-1 ${ }^{-/-} \mathrm{BM}$ grafts had no difference in the number of donor-derived T cells (Figure $6 \mathrm{E}$ ) or mRNA expression of IFN- $\gamma$, IL-6, IL-10, TNF- $\alpha$, or IDO-1 (Figure 6F) when compared with wildtype controls. Conversely, IDO-1 ${ }^{-/-}$recipients that received $\mathrm{MHC}$-incompatible BM grafts had reduced numbers of both $\mathrm{CD}^{+}$and $\mathrm{CD} 8^{+} \mathrm{T}$ cells (Figure 7A), but this was not accompanied by any difference in Tregs (Figure 7B), indicating that absence of host IDO-1 reduced effector T cell accumulation in the brain. In that regard, we also observed a significant decrease in gene expression of IFN- $\gamma$ and IL- 6 , but not TNF- $\alpha$ in IDO- $1^{-/-}$recipients compared with wild-type mice (Figure 7C). IDO-1 mRNA expression was also negligible, consistent with the interpretation that the host was the primary source of this enzyme. Notably, however, we observed no difference in time spent struggling in the FST in IDO- $1^{-/-}$recipient animals compared with wild-type controls (Figure 7D).

Host microglial cells expand during GVHD, produce IDO-1, and are regulated by IL-6. To further characterize the inflammatory environment in the brains of animals with GVHD, we performed immunohistochemical staining with an F4/80 antibody that marks both microglia and macrophages (Figure $8 \mathrm{~A}$ ). F4/80+ cells had long branching processes that are in accord with known microglial cell morphology, and were 

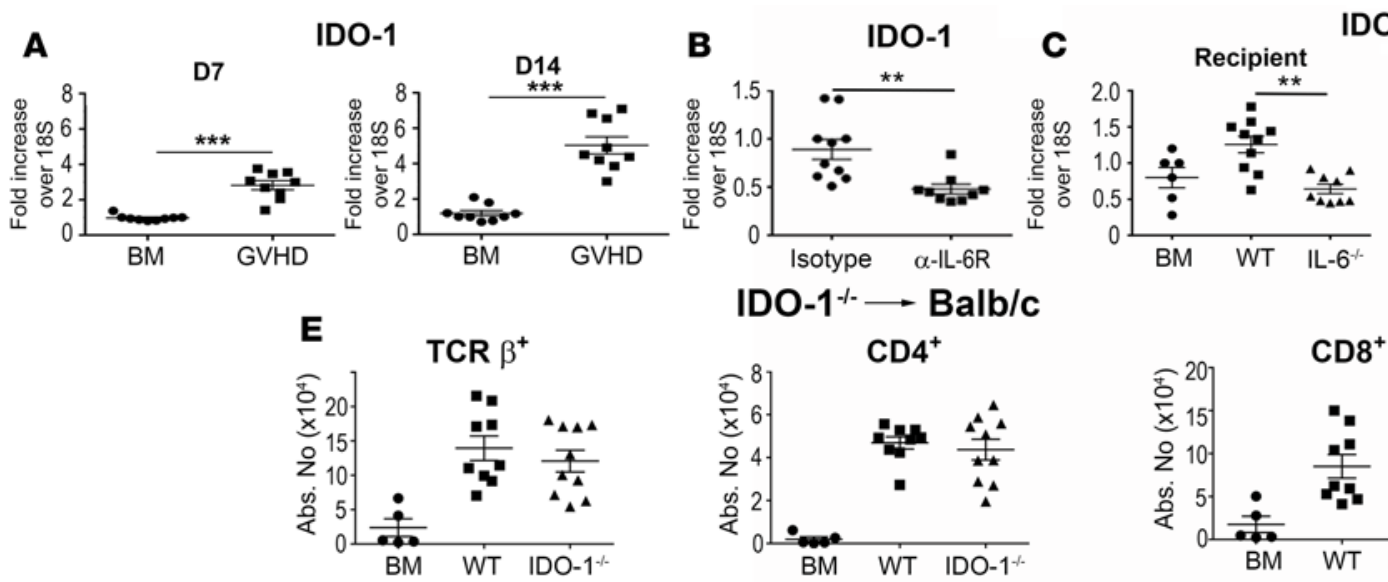

IDO-1
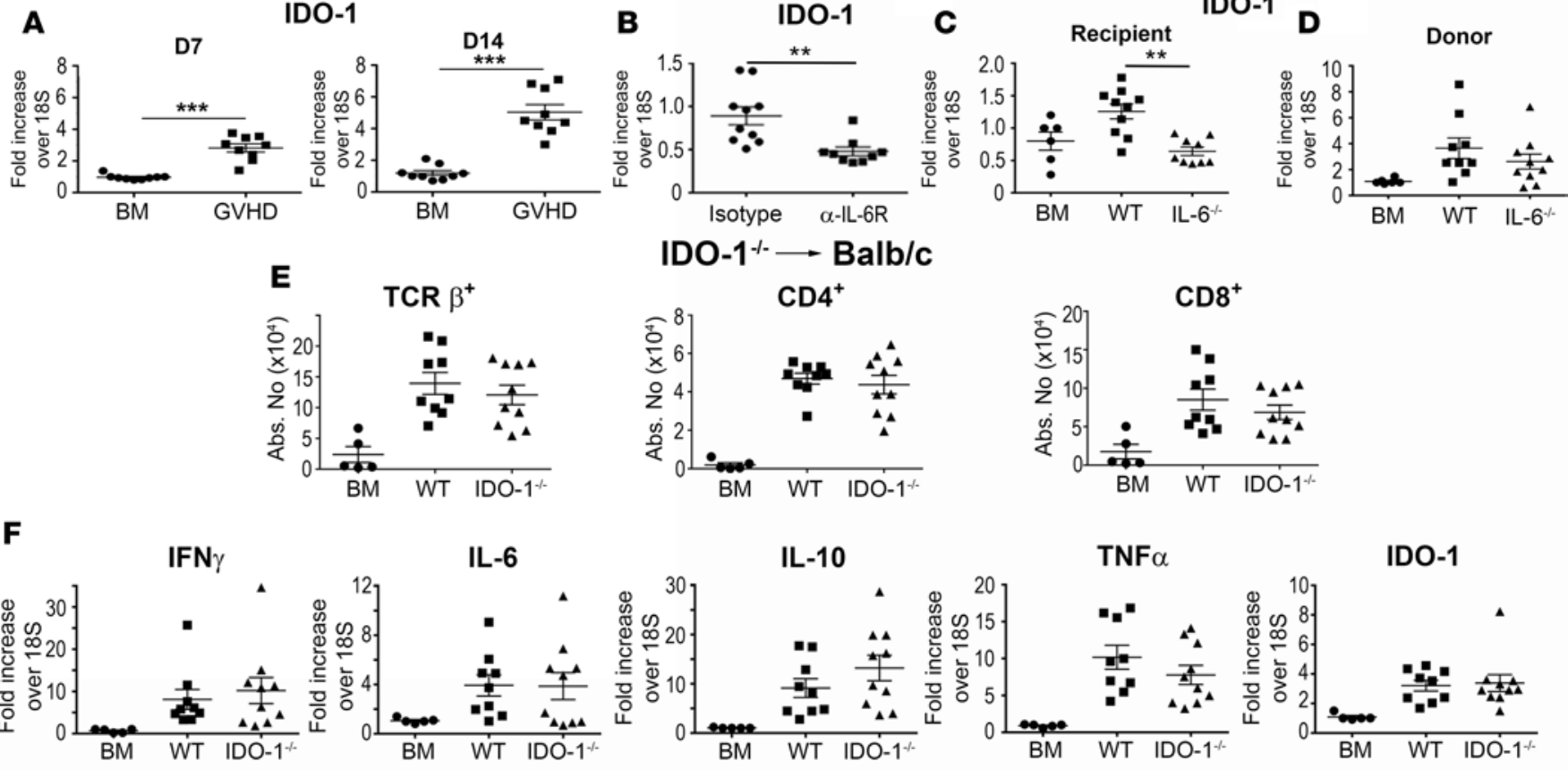

Figure 6. Donor IDO-1 production does not impact inflammation in the brain during graft-versus-host disease (GVHD). IDO-1 mRNA expression in the brains of BALB/c mice transplanted with B6 bone marrow (BM) alone $(\bullet, n=9)$ or B6 BM and B6 spleen cells $(\square, n=9) 7$ and 14 days after transplantation. (B) IDO-1 mRNA expression in the brains of BALB/C recipient mice treated with either an isotype control $(\bullet, n=10)$ or the anti-IL-6 receptor $(\alpha-I L-6 R)$ antibody $(\mathbf{\square}, n=9)$ on days 0 and 7 , and then assessed 14 days after transplantation. (C) IDO-1 mRNA expression in the brains of B6 ( $\mathbf{\square}, n=10)$ or IL-6 $6^{-1-}$ animals transplanted with B10.BR BM and spleen cells (adjusted to a dose of $4.5 \times 10^{6} \alpha \beta$ T cells) $(\boldsymbol{\Lambda}, n=9)$. B6 $(\bullet, n=6)$ mice reconstituted with B10.BR BM alone served as controls. (D) IDO-1 mRNA expression in the brains of BALB/C mice transplanted with either B6 ( $\mathbf{\square}, n=9)$ or IL-6 $6^{-1-} \mathrm{BM}$ and spleen cells ( $\mathbf{\Delta}$, $n=10)$. BALB/c mice reconstituted with B6 BM alone served as controls $(\bullet, n=6)$. (E) BALB/c mice transplanted with B6 BM alone $(\bullet, n=5)$, B6 BM and spleen cells $(\mathbf{\square}, n=9)$, or IDO-1-1- BM and spleen cells $(\boldsymbol{\Lambda}, n=10)$. The absolute number of donor-derived TCR ${ }^{+}, \mathrm{CD}^{+}$, and CD8 $8^{+} \mathrm{T}$ cells in the brain 14 days after transplantation is depicted. (F). IFN- $\gamma$, IL-6, IL-10, TNF- $\alpha$, and IDO-1 mRNA expression in the brains of BALB/C mice transplanted with B6 BM alone (• $n=5)$, B6 BM and spleen cells $(\mathbf{m}, n=10)$, or IL- $6^{-1-} \mathrm{BM}$ and spleen cells $(\boldsymbol{\Delta}, n=10)$ on day 14 . Statistically significant differences were calculated using the 2-tailed Mann-Whitney $U$ test and the 2 -way ANOVA followed by Student's $t$ test. ${ }^{*} P<0.01,{ }^{* * *} P<0.001$.

augmented in GVHD mice (14.2 \pm 11.5 versus $56.0 \pm 12.0 \mathrm{~F} 4 / 80^{+}$cells per 200-micron field in BM $[n$ $=5]$ and GVHD [ $=4]$ animals, respectively, $P<0.05)$. Flow cytometric analysis confirmed that nearly all host cells expressed F4/80 (Figure 8B) and were significantly increased in the brains of GVHD mice (Figure $8 \mathrm{C}$ ). We observed that both $\mathrm{CD} 45^{\mathrm{lo}} \mathrm{CD} 11 \mathrm{~b}^{+}$and $\mathrm{CD} 45^{\mathrm{hi}} \mathrm{CD} 11 \mathrm{~b}^{+}$cells, which mark microglia and macrophages, respectively, were present in the brain (Figure 8D), but that only microglial cells were significantly augmented in GVHD animals (Figure $8 \mathrm{E}$ ). CD $45^{10} \mathrm{CD} 11 \mathrm{~b}^{+}$microglia also uniformly expressed IDO-1 (Figure 8F), defining this cell population as a major source of this enzyme. The classic paradigm for macrophage activation is the characterization of these cells into classically activated (M1) and alternatively activated (M2) phenotypes (33). Microglial cells can also undergo similar polarization, which can modulate inflammatory responses in different disease states $(34,35)$, although this compartmentalized classification has increasingly come into question with respect to both macrophages and microglial cells $(36,37)$. To that end, we observed that M1-associated (Nos2) and M2-associated ( $\mathrm{Ym} 1$, arginase 1) gene expression profiles were significantly increased in both murine models (Figure $8, \mathrm{G}$ and $\mathrm{H}$ ), consistent with a generalized and not phenotypic increase in myeloid-derived cells. Finally, blockade of IL-6 signaling resulted in a significant decrease in the absolute number of microglial cells in the brains of GVHD animals (Figure 8I).

GVHD results in a reduction in neuroprotective IDO-1 metabolites that is not reversed by blockade of IL-6 signaling. Under inflammatory conditions, IDO-1 activity is increased and tryptophan is shuttled down the kynurenine pathway away from serotonin synthesis (Supplemental Figure 3). To further interrogate the tryptophan metabolic pathway, we utilized mass spectrometry to quantify tryptophan metabolites in the brains of animals with GVHD and also examined the effect that blockade of peripheral IL-6 signaling had on these metabolites. We specifically examined the dorsal raphe nucleus (DRN) and the medial prefrontal cortex (mPFC) since the serotoninergic cell bodies reside in the DRN, while the mPFC is 


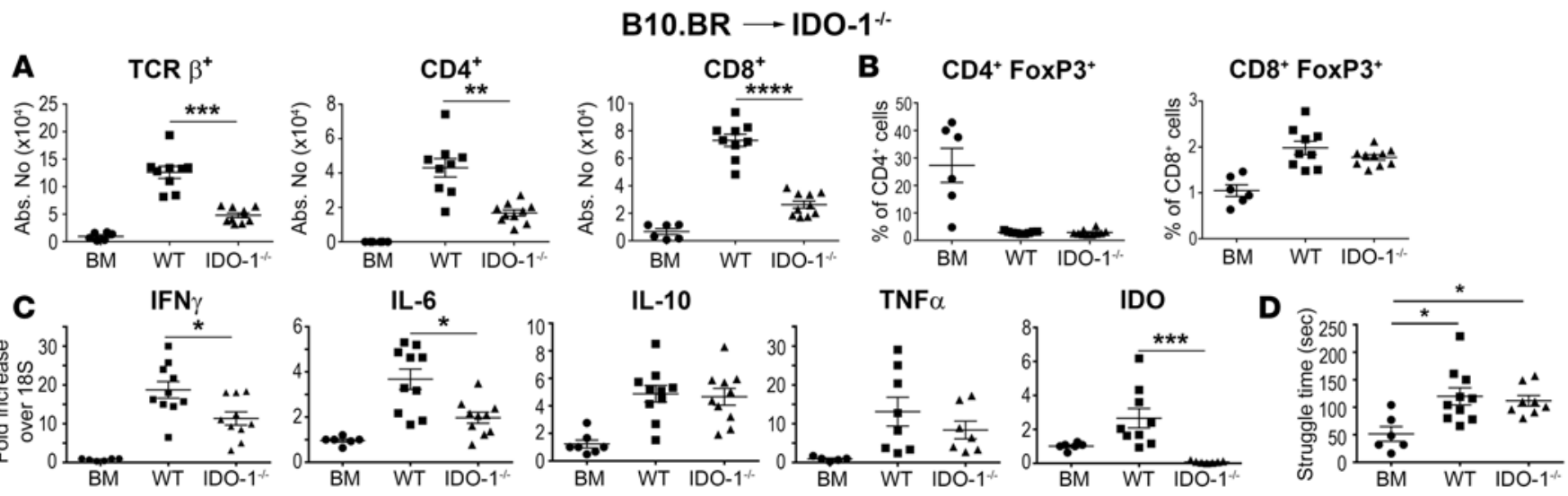

Figure 7. Host IDO-1 production regulates inflammation in the brain during graft-versus-host disease. (A-C). Lethally irradiated (1,100 cGy) B6 ( $\square, n=$ 8-10) or IDO-1-1- $(\boldsymbol{\Lambda}, n=7-10)$ animals were transplanted with B10.BR bone marrow (BM) and spleen cells (adjusted to a dose of $4.5 \times 10^{6} \alpha \beta$ T cells). B6 mice reconstituted with B10.BR BM alone $(\bullet, n=6)$ served as controls. The absolute number of donor-derived TCR $\beta^{+}, \mathrm{CD} 4^{+}$, and CD8 ${ }^{+}$T cells in the brain 14 days after transplantation. (B) The percentage and absolute number of CD4+ Foxp3 $3^{+}$and CD8 ${ }^{+}$Foxp3 $3^{+}$Tregs. (C) IFN- $\gamma$, IL-6, IL-10, TNF- $\alpha$, and IDO-1 mRNA expression in the brain on day 14. (D) Time spent struggling (in seconds) of B6 mice transplanted with B10.BR BM $(\bullet, n=6)$, B6 mice reconstituted with B10.BR BM and spleen cells $(\mathbf{\square}, n=10)$, or ID0-1-1- animals transplanted with B10.BR BM and spleen cells $(\boldsymbol{\Lambda}, n=8)$ in the forced swim test 14 days after transplantation. Results are from 2 experiments in all panels. Statistically significant differences were calculated using the 2 -tailed Mann-Whitney $U$ test and the 2-way ANOVA followed by Student's $t$ test. ${ }^{*} P<0.05,{ }^{* *} P<0.01,{ }^{* * *} P<0.001,{ }^{* * * *} P<0.0001$.

a primary site of serotoninergic innervation and serotonin receptor expression, and is involved in the forced swim behavior (38). We observed that animals with GVHD that were treated with an isotype control antibody had unchanged concentrations of tryptophan and 5-hydroxyindole acetic acid (5-HIAA) compared with BM controls; however, serotonin concentrations were significantly reduced in both the mPFC and DRN (Figure 9, A and B). The turnover of serotonin, as estimated by the ratio of 5-HIAA to serotonin concentration in the same sample, was significantly increased in animals with GVHD compared with BM controls in both brain regions. In accord with an increase in IDO-1 expression, there was a significant increase in kynurenine concentrations in both the DRN and mPFC. Concentrations of 2 kynurenine metabolites, kynurenic acid, which is neuroprotective (39), and 3-hydroxyanthanilic acid, which has both neuroprotective and neurotoxic properties $(40,41)$, were significantly reduced in both brain regions (Figure 9, A and B). Conversely, there was no difference in the concentration of the toxic metabolite, 3-hydroxykynurenine $(42,43)$. Collectively, these studies demonstrated that GVHD results in an accumulation of kynurenine but an overall reduction in its downstream metabolites. When animals were treated with an anti-IL-6R antibody, we observed that there was no difference in serotonin levels, serotonin turnover, or levels of kynurenine, kynurenic acid, 3-hydroxykynurenine, and 3-hydroxyanthranilic acid when compared with isotype antibody control-treated mice. Thus, blockade of IL-6 signaling did not reverse the effects of GVHD on serotonin and tryptophan metabolism.

\section{Discussion}

Cognitive and behavioral alterations are common after allogeneic HSCT and are often associated with coexistent GVHD $(44,45)$. These not infrequently occur in patients that have otherwise been cured of their disease and can profoundly affect quality of life in an adverse manner. The extent to which these alterations are immune mediated or are due to other etiologies is not always clear since the diagnosis of GVHD of the CNS can be challenging for several reasons. First of all, other etiologies, such as infections and medications, can affect behavior and induce cognitive dysfunction after transplantation. In addition, histological confirmation of GVHD in the CNS is problematic, owing to the invasive procedures that are required to procure relevant tissue samples. Consequently, other than anecdotal reports $(20,21)$, there has been little systematic analysis of whether GVHD induces inflammation in the brain and if that can lead to behavioral abnormalities in humans. A number of preclinical studies, however, provide support for the premise that alloreactive donor $\mathrm{T}$ cells can infiltrate the brain during GVHD and be associated with behavioral abnormalities. Hartrampf et al. (18) reported that the CNS was a target organ during GVHD in murine models and was associated with anxiogenic behavior and learning 
A

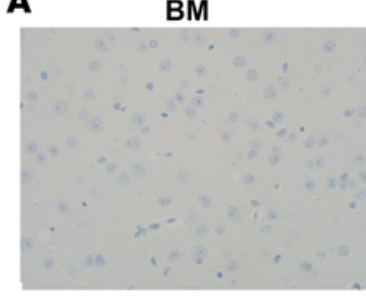

D

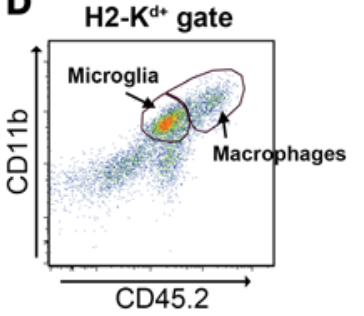

G

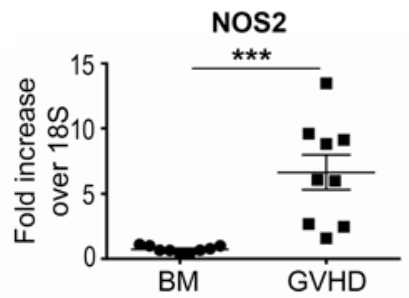

H

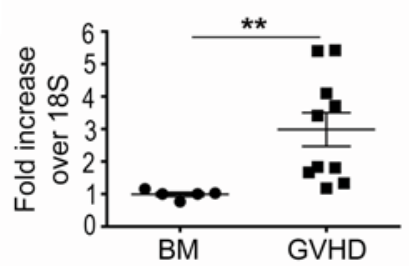

GVHD

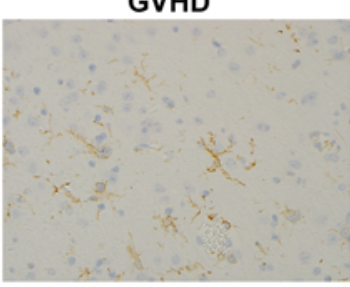

E

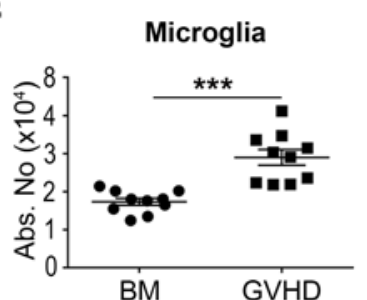

B6 $\longrightarrow$ Balb/c

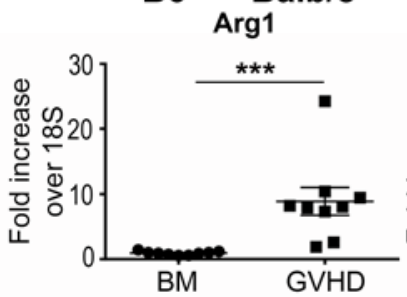

$\mathrm{B} 10 . \mathrm{BR} \longrightarrow \mathrm{B} 6$

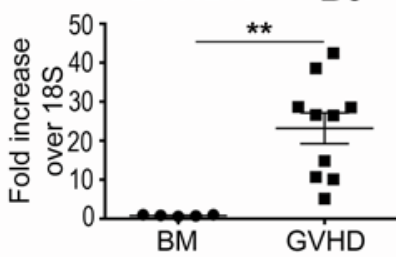

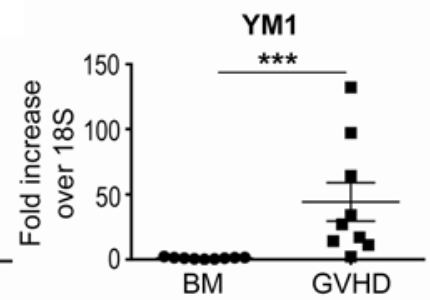

B
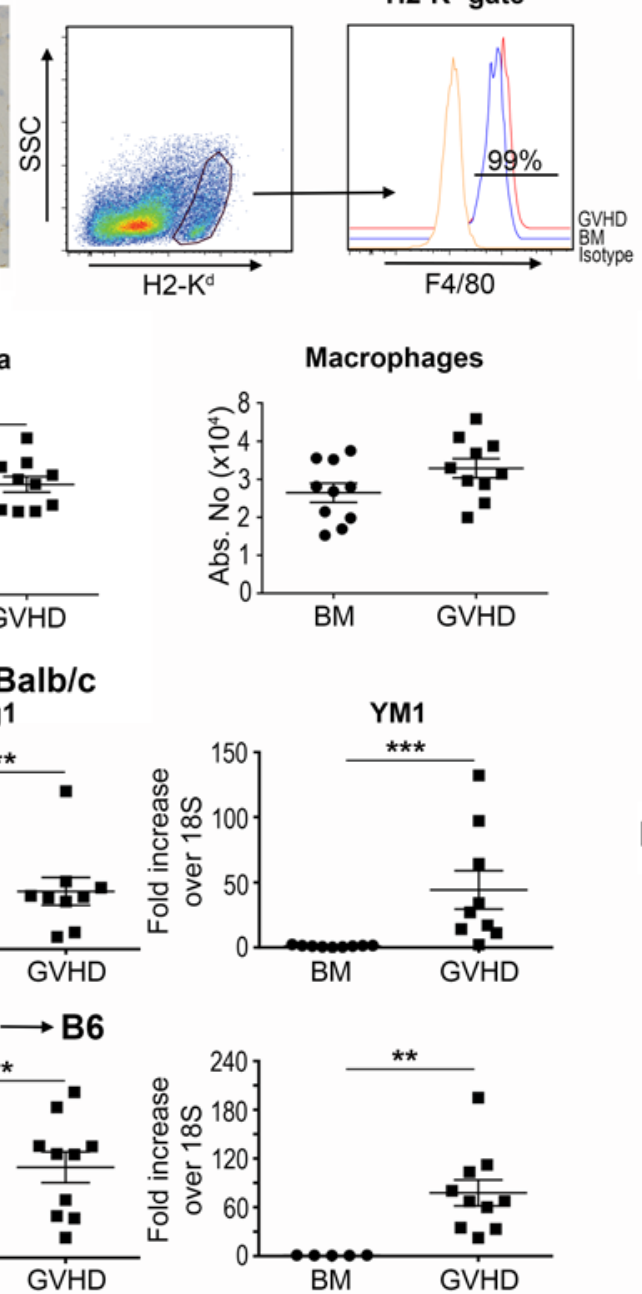

C

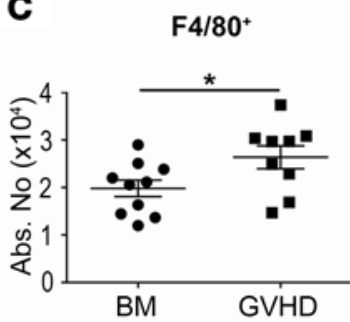

$\mathbf{F}$
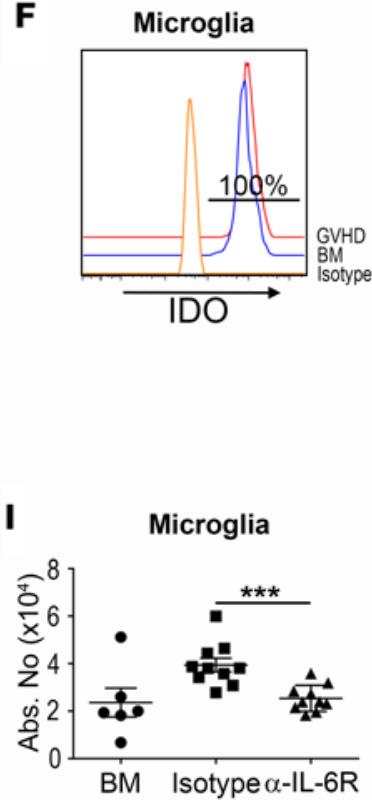

Figure 8. Host microglial cells are increased during graft-versus-host disease (GVHD) and regulated by IL-6. (A) Immunostain of F4/80 expression in the prefrontal cortex from BALB/c mice transplanted with bone marrow (BM) alone or together with B6 spleen cells (adjusted to a dose of $0.6 \times$ $10^{6} \alpha \beta$ T cells) (GVHD). Brown staining denotes F4/80+ cells. Original magnification is $\times 200$. (B) F4/80 expression on host ( $\mathrm{H}-2 \mathrm{~K}{ }^{\mathrm{d}+}$ ) cells from animals transplanted with BM alone or BM and spleen cells (GVHD) 11-12 days after transplantation. Isotype control antibody is shown for comparison.

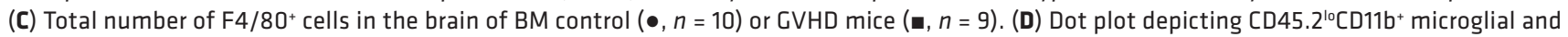
CD45. $2^{\text {hi CD11 }}{ }^{+}$macrophages in the brain from GVHD animals. (E) Total number of microglia and macrophages in the brains from BM control or GVHD animals on day 14. (F) Representative histogram depicting intracellular IDO expression in CD45. $2^{\circ} \mathrm{CD} 11 \mathrm{~b}^{+}$microglial cells derived from BM or GVHD mice. (G) Nos2, Arg1, and Ym1 mRNA expression in the brains of BALB/c mice transplanted with B6 BM alone (•, $n=9)$ or B6 BM and spleen cells (adjusted to a dose of $0.6 \times 10^{6} \alpha \beta$ T cells) $(\mathbf{m}, n=9) 14$ days after transplantation. (H) Nos2, Arg1, and Ym1 mRNA expression in the brains of B6 mice reconstituted with B10.BR BM alone $(\bullet, n=5)$ or with B10.BR spleen cells (adjusted to a dose of $4.5 \times 10^{6} \alpha \beta$ T cells) ( $\mathbf{\square}, n=9$ ). (I) The absolute num-

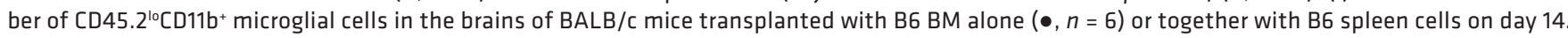
Mice transplanted with B6 BM and spleen cells were treated with either an isotype control ( $\mathbf{\square}, n=10)$ or anti-IL-6 receptor ( $\alpha-$ IL-6R) antibody on days 0 and $7(\boldsymbol{\Delta}, n=10)$. Data are from 2 experiments in all panels. Statistically significant differences were calculated using the 2 -tailed Mann-Whitney $U$ test. ${ }^{*} P<0.05,{ }^{* *} P<0.01,{ }^{* * *} P<0.001$.

deficits. Furthermore, Kaliyaperumal (46) and colleagues reported in a nonhuman primate model that donor $\mathrm{CD}^{+} \mathrm{T}$ cells infiltrated the brain during GVHD and localized primarily to perivascular regions in the meninges. Notably, they observed that GVHD animals had associated behavioral depression and severe lassitude that were not present in primates that were on concurrent immune suppressive therapy, indicating a strong association between $\mathrm{T}$ cell infiltration and behavioral alterations.

In the current study, we have extended these observations by demonstrating that IL-6 plays a pivotal role in mediating inflammation within the CNS. IL- 6 has emerged as a critical cytokine in the pathophysiology of GVHD and as a proximate cytokine mediator for many of the downstream pathological effects observed in this disease. Studies in murine models have demonstrated significantly increased 

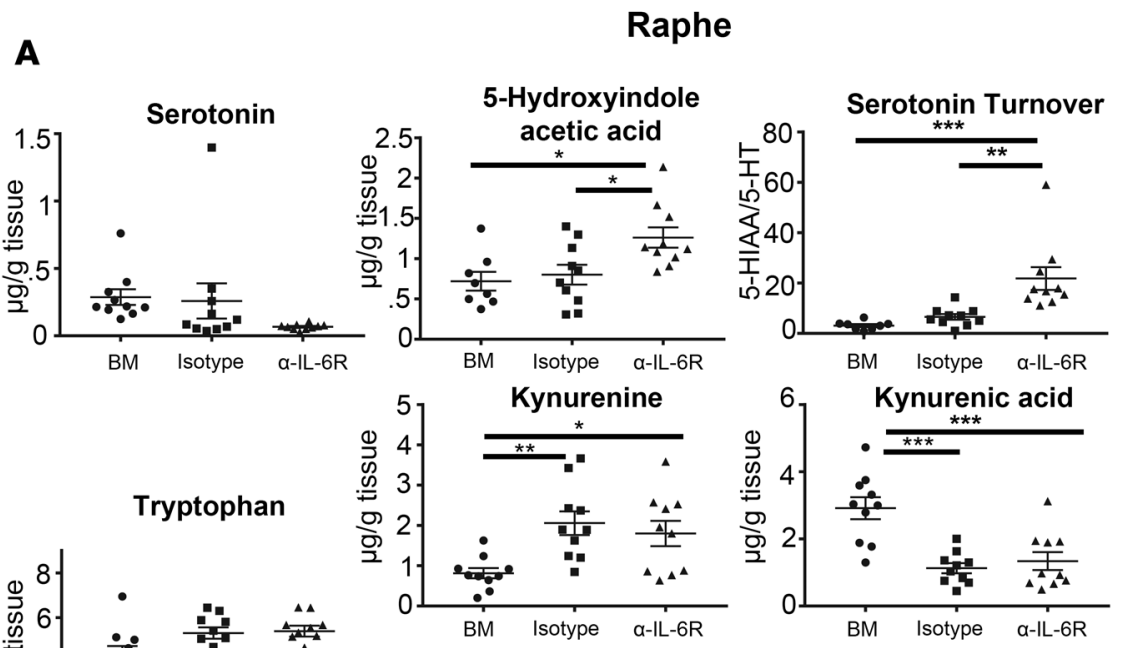

3-Hydroykynurenine
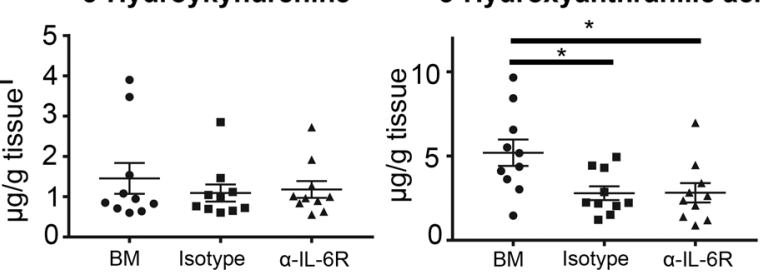

\section{Prefrontal Cortex}
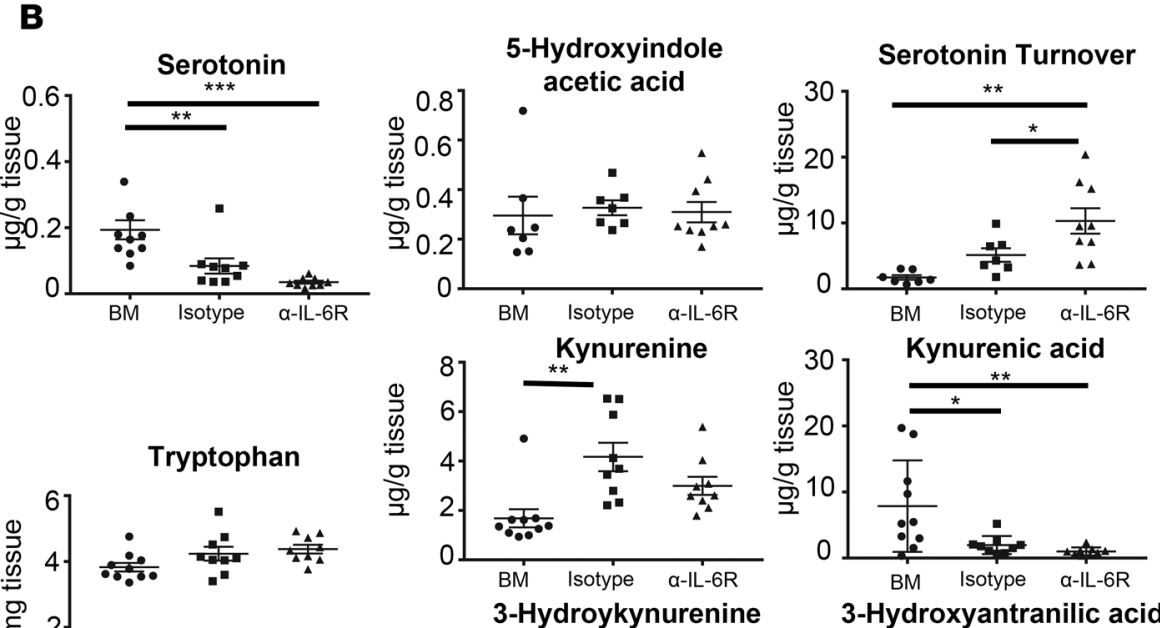

Kynurenic acid

3-Hydroxyantranilic acid
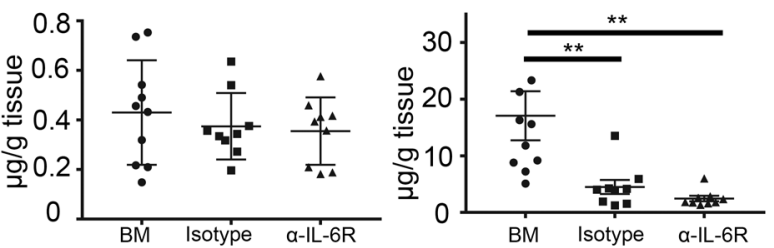

Figure 9. Kynurenines are increased in the brain during graft-versus-host disease. $B A L B / c$ recipients were transplanted with $B 6$ $\mathrm{BM}$ alone $(\bullet, n=10)$ or B6 BM and spleen cells and then treated with an isotype control ( $\mathbf{\square}$, $n=9$ ) or anti-IL-6 receptor ( $\alpha-I L-6 R)$ antibody $(\boldsymbol{\Lambda}, n=9)$. Animals in each cohort were euthanized 14 days after transplantation, and the medial prefrontal cortex and dorsal raphe nucleus were dissected from the brains of transplant recipients. The amount of tryptophan, serotonin, 5-hydroxyindole acetic acid, kynurenine, kynurenic acid, 3-hydroxykynurenic acid, and 3-hydroxyanthranilic acid are depicted in the raphe (A) and prefrontal cortex (B). Data are from 3 experiments. Statistically significant differences were calculated using the 2-way ANOVA, followed by $t$ tests if the interaction was statistically significant. ${ }^{*} P<0.05,{ }^{* *} P<0.01,{ }^{* * *} P<0.001$.

levels of IL-6 in the blood and augmented gene expression of IL- 6 mRNA in peripheral target tissues $(47,48)$. Moreover, we and others have shown that blockade of the IL-6 signaling pathway in mice is able to significantly reduce pathological damage and improve overall survival, in part, owing to enhanced reconstitution of Tregs (47), which results in a recalibration of the effector and regulatory arms of the immune system. Recent clinical studies also support a role for IL- 6 in the pathophysiology of acute GVHD $(49,50)$. Importantly, several studies in experimental nontransplant models have shown that IL-6 partially mediates the psychosocial stress response (51), and elevated IL-6 levels in the periphery have been reported in HSCT patients who suffer from major depression $(52,53)$. The results of the current study support the interpretation that IL-6 plays an important role in promoting inflammation within the CNS as well as inducing behavioral abnormalities. In particular, our data demonstrating that blockade of systemic IL-6 by way of anti-IL-6R antibody administration can reduce a number of parameters of CNS inflammation indicate that IL- 6 production in the periphery modulates the severity of GVHD within the brain.

We observed that both nTregs and iTregs were present in increased numbers in untreated GVHD mice when compared with BM controls, but that the presence of these Tregs was insufficient to prevent neuroinflammation. This was likely due to the fact that there were still 75-150 times more conventional donor $\mathrm{T}$ cells than Tregs in the brains of GVHD animals, indicative of a substantial imbalance between the effector and regulatory arms of the immune system. Notably, inhibition of IL-6 signaling resulted in no significant increase in the absolute number of Tregs and actually effected a reduction in $\mathrm{CD} 8^{+}$Treg numbers. In contrast, the total 
number of conventional $\mathrm{CD} 4^{+}$and $\mathrm{CD} 8^{+} \mathrm{T}$ cells was significantly reduced after administration of anti-IL-6R antibody, indicating that inhibition of IL- 6 signaling served to recalibrate the regulatory and effector arms of the immune system by decreasing effector $\mathrm{T}$ cell numbers. This would also explain the paradoxical reduction in CD8 ${ }^{+}$Tregs after anti-IL-6R antibody administration, since essentially all CD8 ${ }^{+}$Tregs are iTregs and therefore derived from the conventional $\mathrm{CD}^{+} \mathrm{T}$ cell compartment, which was substantially reduced after IL- 6 blockade.

IDO-1, which catalyzes the conversion of tryptophan to metabolites that can be neurotoxic $(54,55)$, is an important downstream pathway by which the inflammatory effects of IL-6 are mediated in the brain. We observed that IDO-1 mRNA levels were significantly increased in the brains of GVHD animals, and this was abrogated when mice were treated with an anti-IL-6R antibody, indicating that the upregulation of IDO-1 expression occurred as a consequence of the actions of IL- 6 in the periphery. Host, but not donor, IDO-1 production was shown to be critical for the immunological abnormalities that occurred in the brain during GVHD. To that end, we determined that microglial cells, which were increased in number during GVHD, express IDO-1, identifying this population as a major source of this enzyme and positioning these cells as important cellular mediators of neuroinflammation during GVHD. Notably, microglial cell numbers were significantly reduced after blockade of peripheral IL- 6 signaling, suggesting that IL-6 regulates microglial cell accumulation. Examination of prototypical M1 and M2 genes revealed that both were significantly augmented in the brains during GVHD, indicating that there was no restricted M1 or M2 phenotype in macrophages and/or microglia. This observation is in accord with recent reevaluation of the validity of this paradigm in vivo under inflammatory conditions $(36,37)$.

Consistent with the GVHD-mediated upregulation of IDO-1, we observed that levels of the IDO1 metabolite, kynurenine, were significantly increased in mice with GVHD in the mPFC and DRN. Conversely, kynurenic acid, which is a neuroprotective kynurenine metabolite (39), was significantly reduced, while 3-hydroxkynurenine, which can induce oxidative damage leading to neurotoxicity (40, 41), was not affected. Notably, levels of 3-hydroxyanthranilic acid, which has been reported to have both neurotoxic and immunosuppressive properties $(39,42,43)$, was also significantly reduced. While these data support an increase in tryptophan metabolism via the IDO-1 pathway, the collective results suggest that any toxicity occurring as a result of this pathway could be due to the preferential loss of neuroprotective, as opposed to the accumulation of neurotoxic, metabolites. Given that anti-IL-6R antibody treatment reduced expression of IDO-1 that is augmented during GVHD, it is noteworthy that anti-IL-6R antibody administration did not normalize kynurenine concentrations, despite the profound effect it had on $\mathrm{T}$ cell accumulation, inflammatory cytokine production, and microglial cell numbers. The reason for this is unclear, although it is possible that kynurenine synthesis could be maintained by a second subtype of IDO, IDO-2, that has also been reported to be expressed in the brain (56). Thus, these results indicate that interruption of the IL- 6 signaling pathway does not reverse all of the immunological and metabolic abnormalities in the brain during GVHD.

Our results may have ramifications beyond GVHD to other conditions where T cell-based immune therapies are associated with behavioral and cognitive dysfunction. For example, the administration of chimeric antigen receptor (CAR) $\mathrm{T}$ cells as an approach to treat a variety of malignant hematological disorders has unfortunately been accompanied by a systemic cytokine release syndrome that can result in clinically significant neuroinflammation and cognitive deficits (57). The precise mechanism by which this complication occurs, however, is not well understood. Notably, while blockade of IL-6 signaling with tocilizumab has been shown to be effective for ameliorating systemic CAR T cell-mediated toxicity (57), it has not been able to prevent the development of neuroinflammation (58). Our observation that IL-6 blockade does not reverse GVHD-induced tryptophan metabolite dysregulation provides a potential explanation for the inability of tocilizumab to completely prevent neurological toxicity in this setting.

Behavioral responses in the FST reflect coping decisions and are modulated by many factors (59) Although the FST was originally developed and used as a behavioral assay for antidepressant efficacy, immobility in the FST, regardless of drug treatment, has been associated with a depressed mood in rodents (22). However, this view is increasingly being challenged and a recent review concludes that the utility of the FST is its sensitivity to response selection (59). We observed a pronounced increase in struggling behavior in the FST in GVHD animals, which is a dysfunctional response, as maintained struggling results in useless expenditure of energy. This effect was markedly attenuated in mice administered anti-IL-6R antibody, a treatment that also significantly reduced $\mathrm{T}$ cell accumulation and inflammatory cytokine production. These findings lead to the conclusion that the behavioral changes result from inflammation-induced dysregulation 
of inputs into the prefrontal cortex. However, although neuroinflammation was also considerably reduced in $\mathrm{IL}_{-} 6^{-/-}$and $\mathrm{IDO}-1^{-/-}$recipient animals, there was no improvement in the FST results, suggesting that an as yet to be identified aspect of the neuroinflammatory response is responsible for this behavioral change. There is considerable evidence that the serotoninergic pathway contributes to the regulation of forced swim behavior (59), and our finding that serotonin turnover was significantly increased in GVHD suggests that the serotoninergic inputs into the prefrontal cortex could be responsible for this behavioral change. However, anti-IL-6R antibody treatment reduced struggling in the FST but produced an even greater increase in serotonin turnover, which argues against a serotonin mechanism for the increased struggling. Thus, further studies are needed to more completely elucidate the inflammatory mechanisms and pathways that mediate this particular behavior in GVHD recipients.

In summary, these studies demonstrated that alloreactive donor $\mathrm{T}$ cells can infiltrate the brain during GVHD, leading to inflammatory cytokine production and behavioral abnormalities. IL-6 has a pivotal role in this pathophysiological process and the downstream effects of this cytokine are mediated, in part, by host microglial cells and IDO-1. While blockade of IL-6 signaling reduced T cell infiltration and inflammatory cytokine production, it did not reverse the dysregulation of IDO-1 metabolism that occurs during GVHD. Thus, inhibition of the peripheral IL-6 signaling pathway with agents such as tocilizumab may not completely abrogate the neuroinflammation that occurs in patients who develop GVHD and is a potential explanation for why tocilizumab fails to completely abrogate CAR T cell-mediated neurotoxicity.

\section{Methods}

Mice. C57BL/6 (B6) (Thy1.2+) (H-2 $\left.{ }^{\mathrm{b}}\right)$, B6.PL (Thy1.1+) $\left(\mathrm{H}-2^{\mathrm{b}}\right), \mathrm{BALB} / \mathrm{c}\left(\mathrm{H}-2^{\mathrm{d}}\right), \mathrm{B} 10 . \mathrm{BR}\left(\mathrm{H}-2^{\mathrm{k}}\right), \mathrm{B} 6$ Foxp3 $3^{\mathrm{EGFP}}$, IL- $6^{-/-}$, and IDO- $1^{-/-}$mice were bred in the Animal Resource Center (ARC) at the Medical College of Wisconsin (MCW) or purchased from Jackson Laboratories. B6 10BiT.Foxp3 ${ }^{\text {EGFP }}$ reporter mice were provided by Casey Weaver (University of Alabama Birmingham) (60). IL-6 $6^{-/-}$Foxp3 $3^{\mathrm{EGFP}}$ mice were created by mating male IL- $6^{-/-}$and female Foxp $3^{\text {EGFP }}$ animals, intercrossing offspring, and then screening by PCR for absence of IL- 6 and presence of EGFP. All animals were housed in the Association for Assessment and Accreditation of Laboratory Animal Care-accredited ARC of the MCW. Mice received regular mouse chow and acidified tap water ad libitum.

Reagents. Anti-IL-6R antibody (MR-16-1) is a rat IgG antibody provided by Chugai Pharmaceutical Co. Ltd (61) that has been previously described (47). Animals received a loading dose of 2 mg intravenously on day 0 , and then were treated with $0.5 \mathrm{mg}$ on day 7 by intraperitoneal injection. Rat IgG (Jackson Immunoresearch Laboratories) was used as a control for MR-16-1.

BM transplantation. BM was flushed from donor femurs and tibias with DMEM (Gibco-BRL) and passed through sterile mesh filters to obtain single-cell suspensions. Red cells were removed from spleen cell suspension by hypotonic lysis using a Tris-buffered ammonium chloride (ACT) solution. Host mice were conditioned with total body irradiation (TBI) administered as a single exposure at a dose rate of 9001,100 cGy using a Shepherd Mark I Cesium Irradiator (J.L. Shepherd and Associates). Irradiated recipients received a single intravenous injection in the lateral tail vein of BM with or without added spleen or purified $\mathrm{T}$ cells. $\mathrm{T}$ cells were purified by either magnetic beads using a pan $\mathrm{T}$ cell isolation column (Miltenyi Biotec), or by cell sorting. Mice were weighed 3 times per week and were euthanized when they attained predefined morbidity criteria.

Isolation of lymphocyte populations. Lymphocytes were isolated from the brain by collagenase $\mathrm{D}$ digestion (Roche Pharmaceuticals) supplemented with DNAse $(0.2 \mathrm{mg} / \mathrm{ml})$ (Roche). The resulting cell suspension was then layered on a 40\%/70\% Percoll gradient (GE Healthcare Biosciences). Cell counts were obtained from half of the brain for each experimental animal unless otherwise specified.

Flow cytometry. Isolated lymphocytes from the brain were labeled with monoclonal antibodies for flow cytometry, as listed in Supplemental Table 1. Cells were then acquired on a BD LSRII flow cytometer with BD FACSDiva software (Becton-Dickenson) and analyzed using FlowJo software (Tree Star).

Intracellular staining. Using monoclonal antibodies listed in Supplemental Table 1, cells were surface stained and then intracellularly stained using the FoxP3/Transcription Factor Staining Buffer Set (eBioscience) or the Cytofix/Cytoperm kit (BD Biosciences) for IDO-1 staining, according to the manufacturer's instructions.

Immunohistochemistry. Representative samples of brain were placed into neutral buffered formalin for 1 week, and then dehydrated and embedded in paraffin following standard protocols. Four-micron sections of paraffin-embedded tissue were cut, and then paraffin was removed and rehydrated. For identification of 
$\mathrm{CD}^{+} \mathrm{T}$ cells, antigen retrieval was carried out at $\mathrm{pH} 9.0$, while the $\mathrm{pH}$ was 6.0 for $\mathrm{F} 480$ detection. A rabbit primary polyclonal antibody was used for CD3 staining (DAKO, Agilent Technologies) (catalog A0452) at a 1:100 dilution, whereas a rat polyclonal antibody was employed for F4/80 staining (Bio-Rad) (catalog MCA497R) at a dilution of 1:250. Biotinylated secondary antibodies raised against rabbit or rat were then employed, followed by incubation with streptavidin conjugated to horseradish peroxidase (HRP). Diaminobenzidine $(\mathrm{DAB})$ was added as the substrate and cells were counterstained with hematoxylin. Cell counting was accomplished by importing the images into ImageJ software (NIH) and was carried out by an observer blinded to treatment. Images were acquired with an Olympus BX53 microscope with an Olympus DP72 camera and cellSens standard software (version 1.5).

Real-time q-PCR. Real-time q-PCR was performed using a QuantiTect SYBR Green PCR Kit (Qiagen) and run in a CFX C1000 Real-time Thermal Cycler (Bio-Rad). The 18S reference gene was amplified using a QuantiTect Primer Assay Kit (Qiagen). The primer sequences for IL-6, IFN- $\gamma$, IL-10, TNF- $\alpha$, and IDO-1 were purchased from Integrated DNA Technologies and are listed in Supplemental Table 2. Specificity for all q-PCR reactions was verified by melting curve analysis. To calculate fold change in gene expression, the average $\Delta \Delta \mathrm{Ct}$ values from triplicate wells were combined from separate experiments.

Behavioral testing. The FST was administered to assess coping strategy in the face of inescapable stress as described previously (62). Mice were placed individually in 700-800 $\mathrm{ml}$ of tap water at $24 \pm$ $2^{\circ} \mathrm{C}$ for 6 minutes and behaviors were recorded. Scorers blinded to experimental group determined the time spent struggling and time in which animals were immobile during the last 5 minutes of the test. Immobility was defined as no movement other than that required to maintain balance or keep the animal's head above water. Anxiety-like behaviors were examined using the EPM assay as described previously (63). Briefly, a plastic maze consisting of 2 open arms $(30 \times 5 \mathrm{~cm})$ and 2 closed arms $(30 \times 5 \times 15$ $\mathrm{cm}$ ) extending from an open, central platform. The mice were placed on the central platform facing an open arm and allowed 5 minutes of free exploration on the apparatus. The movement of the mouse on the maze was recorded and was scored using Any-maze Video Tracking Software (Stoelting Co.). Time spent in the open and closed arms, total arm entries, and number of entries into the open and closed arms were counted for each mouse.

Mass spectrophotometric analysis. The quantification of biogenic amines and selected metabolites was carried out using multiple reaction monitoring (MRM) liquid chromatography-tandem mass spectrometry (LC-MS/MS) of samples that were subjected to chemical derivatization using benzoyl chloride following the method of Zheng et al. (64). Mouse brains were harvested, dissected, and weighed. Tissues were homogenized using glass rods in $100 \mu \mathrm{l}$ of water containing $20 \mathrm{mM}$ ascorbic acid, $50 \mathrm{ng}$ of caffeic acid, and $50 \mathrm{ng}$ of deuterated tryptophan (d5-Tryp; Cayman Chemical Company). The mixtures were sonicated in an ice bath for 30 minutes, followed by the addition of $520 \mu \mathrm{l}$ of ice-cold acetonitrile. After vortexing, the samples were centrifuged and the supernatant was transferred to glass tubes and was evaporated under $\mathrm{N}_{2}$. Twenty-five microliters of $100 \mathrm{mM}$ sodium tetraborate was added to the dried samples, followed by the addition of $25 \mu 1$ of $2 \%$ benzoyl chloride in acetonitrile. Samples were vortexed for 5 minutes, and then centrifuged for 15 minutes at $1,135 \mathrm{~g}$. Thirty microliters of the resulting supernatant was transferred to an LC/MS vial with a glass insert; $5 \mu \mathrm{l}$ was injected for analysis. LC-MS/MS analysis was carried out using an Agilent 6460 Triple Quad LC/MS. The chromatographic separation was carried out using a Kromasil C18 column; the mobile phase consisted of solvent A ( $0.1 \%$ formic acid and $2.0 \mathrm{mM}$ ammonium acetate in water) and solvent B (acetonitrile). The mobile phase was eluted at $0.2 \mathrm{ml} / \mathrm{min}$ following the gradient reported in Zheng et al. (64). Standard curves were constructed from 5-6 concentrations of each analyte; the range was $8-8,000 \mathrm{ng} / \mathrm{ml}$ for tryptophan and $4-2,000 \mathrm{ng} / \mathrm{ml}$ for all of the others. $\mathrm{d} 5$-Tryp was used as the internal standard to assess tryptophan concentrations; caffeic acid was used for all of the others. The electrospray ionization source was operated in the positive mode. The MRM parameters for the analytes investigated are shown in Supplemental Table 3.

Statistics. Statistical analyses were performed with GraphPad Prism 5.00 software. Mann-Whitney $U$ tests were used to compare $\mathrm{T}$ cell populations, gene expression, and mass spectrometry data between the different experimental groups. Behavioral data were analyzed using 2-way ANOVA, followed by 2-tailed Student's $t$ tests if the interaction was statistically significant. Results were considered significant at a $P$ value of 0.05 or less in all experiments.

Study approval. All murine experiments were all carried out under protocols approved by the MCW Institutional Animal Care and Use Committee (Milwaukee, WI). 


\section{Author contributions}

LB performed animal studies, flow cytometric analysis, and helped write the manuscript. VZ, MB, KLS, and ES performed research and analyzed data. CW provided the B6 10BiT.Foxp3 ${ }^{\mathrm{EGFP}}$ reporter mice. ML performed pathological analysis of tissue samples. $\mathrm{MH}$ is an employee of Chugai Pharmaceuticals Co. Ltd. and provided critical reagents. JMK, CJH, and WRD developed the overall concept, designed experiments, supervised the study, and wrote the manuscript.

\section{Acknowledgments}

This research was supported by a grant from the NIH (HL064603) (W.R.D.), an award from the Midwest Athletes against Childhood Cancer Fund (W.R.D.), and a grant from the Advancing a Healthier Wisconsin Endowment (W.R.D. and C.J.H.). L.B. was supported by a grant from the Wallonia Brussels International. J.M.K. received salary support from the National Center for Advancing Translational Sciences, NIH, through grant numbers UL1TR001436 and KL2TR001438. Its contents are solely the responsibility of the authors and do not necessarily represent the official views of the NIH. We thank Rachel Lange and the Department of Pharmacology Mass Spectroscopy Facility for assistance with the mass spectrometric analysis.

Address correspondence to: William R. Drobyski, Bone Marrow Transplant Program, 9200 West Wisconsin Avenue, Milwaukee, Wisconsin 53226, USA. Phone: 414.456.4941; Email: wdrobysk@mcw.edu.

1. Shlomchik WD. Graft-versus-host disease. Nat Rev Immunol. 2007;7(5):340-352.

2. Welniak LA, Blazar BR, Murphy WJ. Immunobiology of allogeneic hematopoietic stem cell transplantation. Annu Rev Immunol. 2007;25:139-170

3. Ferrara JL, Levine JE, Reddy P, Holler E. Graft-versus-host disease. Lancet. 2009;373(9674):1550-1561.

4. Hill GR, Crawford JM, Cooke KR, Brinson YS, Pan L, Ferrara JL. Total body irradiation and acute graft-versus-host disease: the role of gastrointestinal damage and inflammatory cytokines. Blood. 1997;90(8):3204-3213.

5. Xun CQ, Thompson JS, Jennings CD, Brown SA, Widmer MB. Effect of total body irradiation, busulfan-cyclophosphamide, or cyclophosphamide conditioning on inflammatory cytokine release and development of acute and chronic graft-versus-host disease in H-2-incompatible transplanted SCID mice. Blood. 1994;83(8):2360-2367.

6. Teshima T, et al. Acute graft-versus-host disease does not require alloantigen expression on host epithelium. Nat Med. 2002;8(6):575-581.

7. Mowat AM. Antibodies to IFN-gamma prevent immunologically mediated intestinal damage in murine graft-versus-host reaction. Immunology. 1989;68(1):18-23.

8. Burman AC, et al. IFNgamma differentially controls the development of idiopathic pneumonia syndrome and GVHD of the gastrointestinal tract. Blood. 2007;110(3):1064-1072.

9. Nestel FP, Price KS, Seemayer TA, Lapp WS. Macrophage priming and lipopolysaccharide-triggered release of tumor necrosis factor alpha during graft-versus-host disease. J Exp Med. 1992;175(2):405-413.

10. Chen X, Vodanovic-Jankovic S, Johnson B, Keller M, Komorowski R, Drobyski WR. Absence of regulatory T-cell control of TH1 and TH17 cells is responsible for the autoimmune-mediated pathology in chronic graft-versus-host disease. Blood. 2007;110(10):3804-3813.

11. Carlson MJ, West ML, Coghill JM, Panoskaltsis-Mortari A, Blazar BR, Serody JS. In vitro-differentiated TH17 cells mediate lethal acute graft-versus-host disease with severe cutaneous and pulmonary pathologic manifestations. Blood. 2009;113(6):1365-1374.

12. Pidala J, Anasetti C, Jim H. Quality of life after allogeneic hematopoietic cell transplantation. Blood. 2009;114(1):7-19.

13. Sun CL, Francisco L, Baker KS, Weisdorf DJ, Forman SJ, Bhatia S. Adverse psychological outcomes in long-term survivors of hematopoietic cell transplantation: a report from the Bone Marrow Transplant Survivor Study (BMTSS). Blood. 2011;118(17):4723-4731.

14. Pidala J, et al. Patient-reported quality of life is associated with severity of chronic graft-versus-host disease as measured by NIH criteria: report on baseline data from the Chronic GVHD Consortium. Blood. 2011;117(17):4651-4657.

15. Fraser CJ, et al. Impact of chronic graft-versus-host disease on the health status of hematopoietic cell transplantation survivors: a report from the Bone Marrow Transplant Survivor Study. Blood. 2006;108(8):2867-2873.

16. Loberiza FR, et al. Association of depressive syndrome and early deaths among patients after stem-cell transplantation for malignant diseases. J Clin Oncol. 2002;20(8):2118-2126.

17. Arai S, et al. Increasing incidence of chronic graft-versus-host disease in allogeneic transplantation: a report from the Center for International Blood and Marrow Transplant Research. Biol Blood Marrow Transplant. 2015;21(2):266-274.

18. Hartrampf S, et al. The central nervous system is a target of acute graft versus host disease in mice. Blood. 2013;121(10):1906-1910

19. Sostak P, Reich P, Padovan CS, Gerbitz A, Holler E, Straube A. Cerebral endothelial expression of adhesion molecules in mice with chronic graft-versus-host disease. Stroke. 2004;35(5):1158-1163.

20. Kamble RT, Chang CC, Sanchez S, Carrum G. Central nervous system graft-versus-host disease: report of two cases and literature review. Bone Marrow Transplant. 2007;39(1):49-52.

21. Saad AG, Alyea EP, Wen PY, Degirolami U, Kesari S. Graft-versus-host disease of the CNS after allogeneic bone marrow transplantation. J Clin Oncol. 2009;27(30):e147-e149.

22. Porsolt RD, Bertin A, Jalfre M. "Behavioural despair" in rats and mice: strain differences and the effects of imipramine. Eur $J$ Pharmacol. 1978;51(3):291-294. 
23. Hoffmann P, Ermann J, Edinger M, Fathman CG, Strober S. Donor-type CD4(+)CD25(+) regulatory T cells suppress lethal acute graft-versus-host disease after allogeneic bone marrow transplantation. J Exp Med. 2002;196(3):389-399.

24. Bay-Richter $\mathrm{C}$, et al. Behavioural and neurobiological consequences of macrophage migration inhibitory factor gene deletion in mice. J Neuroinflammation. 2015;12:163.

25. Dantzer R, O'Connor JC, Freund GG, Johnson RW, Kelley KW. From inflammation to sickness and depression: when the immune system subjugates the brain. Nat Rev Neurosci. 2008;9(1):46-56.

26. Spooren A, et al. Interleukin-6, a mental cytokine. Brain Res Rev. 2011;67(1-2):157-183.

27. Van Wagoner NJ, Benveniste EN. Interleukin-6 expression and regulation in astrocytes. J Neuroimmunol. 1999;100(1-2):124-139.

28. Erta M, Quintana A, Hidalgo J. Interleukin-6, a major cytokine in the central nervous system. Int J Biol Sci. 2012;8(9):1254-1266.

29. Sparkman NL, Buchanan JB, Heyen JR, Chen J, Beverly JL, Johnson RW. Interleukin-6 facilitates lipopolysaccharide-induced disruption in working memory and expression of other proinflammatory cytokines in hippocampal neuronal cell layers. $J$ Neurosci. 2006;26(42):10709-10716.

30. $\mathrm{Kim} \mathrm{H}$, et al. Brain indoleamine 2,3-dioxygenase contributes to the comorbidity of pain and depression. J Clin Invest. 2012;122(8):2940-2954.

31. O'Connor JC, et al. Interferon-gamma and tumor necrosis factor-alpha mediate the upregulation of indoleamine 2,3-dioxygenase and the induction of depressive-like behavior in mice in response to bacillus Calmette-Guerin. J Neurosci. 2009;29(13):4200-4209

32. Raison CL, Capuron L, Miller AH. Cytokines sing the blues: inflammation and the pathogenesis of depression. Trends Immunol. 2006;27(1):24-31.

33. Varol C, Mildner A, Jung S. Macrophages: development and tissue specialization. Annu Rev Immunol. 2015;33:643-675.

34. Maresz K, Carrier EJ, Ponomarev ED, Hillard CJ, Dittel BN. Modulation of the cannabinoid CB2 receptor in microglial cells in response to inflammatory stimuli. J Neurochem. 2005;95(2):437-445.

35. Wlodarczyk A, et al. Pathologic and protective roles for microglial subsets and bone marrow- and blood-derived myeloid cells in central nervous system inflammation. Front Immunol. 2015;6:463.

36. Martinez FO, Gordon S. The M1 and M2 paradigm of macrophage activation: time for reassessment. F1000Prime Rep. 2014;6:13.

37. Ransohoff RM. A polarizing question: do M1 and M2 microglial exist? Nat Neurosci. 2016;19(8):987-991.

38. Maes M, Leonard BE, Myint AM, Kubera M, Verkerk R. The new '5-HT' hypothesis of depression: cell-mediated immune activation induces indoleamine 2,3-dioxygenase, which leads to lower plasma tryptophan and an increased synthesis of detrimental tryptophan catabolites (TRYCATs), both of which contribute to the onset of depression. Prog Neuropsychopharmacol Biol Psychiatry. 2011;35(3):702-721.

39. Vécsei L, Szalárdy L, Fülöp F, Toldi J. Kynurenines in the CNS: recent advances and new questions. Nat Rev Drug Discov. 2013;12(1):64-82.

40. Hayashi T, et al. 3-Hydroxyanthranilic acid inhibits PDK1 activation and suppresses experimental asthma by inducing T cell apoptosis. Proc Natl Acad Sci U S A. 2007;104(47):18619-18624.

41. Krause D, et al. The tryptophan metabolite 3-hydroxyanthranilic acid plays anti-inflammatory and neuroprotective roles during inflammation: role of hemeoxygenase-1. Am J Pathol. 2011;179(3):1360-1372.

42. Okuda S, Nishiyama N, Saito H, Katsuki H. 3-Hydroxykynurenine, an endogenous oxidative stress generator, causes neuronal cell death with apoptotic features and region selectivity. J Neurochem. 1998;70(1):299-307.

43. Braidy N, Grant R, Adams S, Guillemin GJ. Neuroprotective effects of naturally occurring polyphenols on quinolinic acidinduced excitotoxicity in human neurons. FEBS J. 2010;277(2):368-382.

44. Knight JM, Lyness JM, Sahler OJ, Liesveld JL, Moynihan JA. Psychosocial factors and hematopoietic stem cell transplantation: potential biobehavioral pathways. Psychoneuroendocrinology. 2013;38(11):2383-2393.

45. Costanzo ES, Juckett MB, Coe CL. Biobehavioral influences on recovery following hematopoietic stem cell transplantation. Brain Behav Immun. 2013;30 Suppl:S68-S74.

46. Kaliyaperumal S, et al. CD8-predominant T-cell CNS infiltration accompanies GVHD in primates and is improved with immunoprophylaxis. Blood. 2014;123(12):1967-1969.

47. Chen X, et al. Blockade of interleukin-6 signaling augments regulatory T-cell reconstitution and attenuates the severity of graftversus-host disease. Blood. 2009;114(4):891-900.

48. Tawara I, et al. Interleukin-6 modulates graft-versus-host responses after experimental allogeneic bone marrow transplantation Clin Cancer Res. 2011;17(1):77-88.

49. Drobyski WR, et al. Tocilizumab for the treatment of steroid refractory graft-versus-host disease. Biol Blood Marrow Transplant. 2011;17(12):1862-1868.

50. Kennedy GA, et al. Addition of interleukin-6 inhibition with tocilizumab to standard graft-versus-host disease prophylaxis after allogeneic stem-cell transplantation: a phase 1/2 trial. Lancet Oncol. 2014;15(13):1451-1459.

51. Hodes GE, et al. Individual differences in the peripheral immune system promote resilience versus susceptibility to social stress. Proc Natl Acad Sci U S A. 2014;111(45):16136-16141.

52. Knight JM, et al. Circulating endocannabinoids during hematopoietic stem cell transplantation: a pilot study. Neurobiol Stress. $2015 ; 2: 44-50$

53. Tavakoli-Ardakani M, Mehrpooya M, Mehdizadeh M, Hajifathali A, Abdolahi A. Association between Interlukin-6 (IL-6), Interlukin-10 (IL-10) and depression in patients undergoing Hematopoietic stem cell transplantation. Int J Hematol Oncol Stem Cell Res. 2015;9(2):80-87.

54. Wichers MC, Koek GH, Robaeys G, Verkerk R, Scharpé S, Maes M. IDO and interferon-alpha-induced depressive symptoms: a shift in hypothesis from tryptophan depletion to neurotoxicity. Mol Psychiatry. 2005;10(6):538-544.

55. Schwarcz R, Bruno JP, Muchowski PJ, Wu HQ. Kynurenines in the mammalian brain: when physiology meets pathology. Nat Rev Neurosci. 2012;13(7):465-477.

56. Fukunaga M, et al. Studies on tissue and cellular distribution of indoleamine 2,3-dioxygenase 2: the absence of IDO1 upregulates IDO2 expression in the epididymis. J Histochem Cytochem. 2012;60(11):854-860.

57. Lee DW, et al. Current concepts in the diagnosis and management of cytokine release syndrome. Blood. 2014;124(2):188-195. 
58. Brudno JN, Kochenderfer JN. Toxicities of chimeric antigen receptor T cells: recognition and management. Blood. 2016;127(26):3321-3330.

59. Bogdanova OV, Kanekar S, D'Anci KE, Renshaw PF. Factors influencing behavior in the forced swim test. Physiol Behav. 2013;118:227-239.

60. Maynard CL, et al. Regulatory T cells expressing interleukin 10 develop from Foxp ${ }^{+}$and Foxp3 precursor cells in the absence of interleukin 10. Nat Immunol. 2007;8(9):931-941.

61. Okazaki M, Yamada Y, Nishimoto N, Yoshizaki K, Mihara M. Characterization of anti-mouse interleukin-6 receptor antibody. Immunol Lett. 2002;84(3):231-240.

62. Roberts CJ, Stuhr KL, Hillard CJ. Swim stress differentially affects limbic contents of 2-arachidonoylglycerol and 2-oleoylglycerol. Neuroscience. 2012;204:74-82.

63. Patel S, Hillard CJ. Pharmacological evaluation of cannabinoid receptor ligands in a mouse model of anxiety: further evidence for an anxiolytic role for endogenous cannabinoid signaling. J Pharmacol Exp Ther. 2006;318(1):304-311.

64. Zheng X, et al. Quantitative analysis of neurochemical panel in rat brain and plasma by liquid chromatography-tandem mass spectrometry. Anal Chem. 2012;84(22):10044-10051. 